\title{
Mesozoic lacewings from China provide phylogenetic insight into evolution of the Kalligrammatidae (Neuroptera)
}

\author{
Qiang Yang ${ }^{1,4}$, Yongjie Wang ${ }^{1 *}$, Conrad C Labandeira ${ }^{1,2,3}$, Chungkun Shih ${ }^{1}$ and Dong Ren ${ }^{{ }^{*}}$
}

\begin{abstract}
Background: The Kalligrammatidae are distinctive, large, conspicuous, lacewings found in Eurasia from the Middle Jurassic to mid Early Cretaceous. Because of incomplete and often inadequate fossil preservation, an absence of detailed morphology, unclear relationships, and unknown evolutionary trends, the Kalligrammatidae are poorly understood.

Results: We describe three new subfamilies, four new genera, twelve new species and four unassigned species from the late Middle Jurassic Jiulongshan and mid Early Cretaceous Yixian Formations of China. These kalligrammatid taxa exhibit diverse morphological characters, such as mandibulate mouthparts in one major clade and siphonate mouthparts in the remaining four major clades, the presence or absence of a variety of distinctive wing markings such as stripes, wing spots and eyespots, as well as multiple major wing shapes. Based on phylogenetic analyses, the Kalligrammatidae are divided into five principal clades: Kalligrammatinae Handlirsch, 1906, Kallihemerobiinae Ren \& Engel, 2008, Meioneurinae subfam. nov., Oregrammatinae subfam. nov. and Sophogrammatinae subfam. nov., each of which is accorded subfamily-level status. Our results show significant morphological and evolutionary differentiation of the Kalligrammatidae family during a 40 million-year-interval of the mid Mesozoic.
\end{abstract}

Conclusion: A new phylogeny and classification of five subfamilies and their constituent genera is proposed for the Kalligrammatidae. These diverse, yet highly specialized taxa from northeastern China suggest that eastern Eurasia likely was an important diversification center for the Kalligrammatidae. Kalligrammatids possess an extraordinary morphological breadth and panoply of adaptations during the mid-Mesozoic that highlight our conclusion that their evolutionary biology is much more complex than heretofore realized.

Keywords: Jiulongshan formation, Yixian formation, Mouthparts, Wing eyespots, Phylogenetic analysis, Classification

\section{Background}

The Kalligrammatidae are occasionally referred to as "butterflies of the Jurassic" [1] because of their large size and wingspans, presence of wings with patterned surfaces, including eyespots, and long maxillary palps. These features provide an appearance similar to some large, modern lepidopterans [1]. Kalligrammatids also have a mosaic of structural features displayed in other, various neuropterans. Their siphonate, long-proboscid mouthparts reported here for the first time, do not occur

\footnotetext{
* Correspondence: wangyjosmy@gmail.com; rendong@mail.cnu.edu.cn ${ }^{1}$ College of Life Sciences, Capital Normal University, Beijing 100048, China Full list of author information is available at the end of the article
}

in modern Neuroptera, although the long, curved and lanciform ovipositor that occurs in Oregramma illecebrosa sp. nov. also is present among the modern pleasing lacewings of the Dilaridae [2]. Nevertheless, kalligrammatid lacewings, known only as compression fossils from the late Middle Jurassic (165 Ma) to mid Early Cretaceous $(125 \mathrm{Ma})$, are an insect clade that exhibited a wide spectrum of diverse forms and appearances during the mid-Mesozoic, with 15 genera previously reported from Eurasia, including Western Europe, Central Asia, and Northeastern China [3-28] (Table 1).

Although the Kalligrammatidae are readily identified by their distinctive appearance, there still are no definitive, conventional diagnoses available. Some genera and

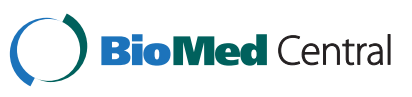


Table 1 Hierarchical classification of the $\mathbf{4 9}$ documented species of Kalligrammatidae ${ }^{1}$

\begin{tabular}{l}
\hline Family Kalligrammatidae \\
\hline Subfamily Kalligrammati \\
Angarogramma [28] \\
A. incertum [28] \\
Kalligramma [9] \\
K. brachyrhyncha sp. nov. \\
K. circularia sp. nov. \\
K. flexuosum [15] \\
K. haeckeli [9] \\
K. jurarchegonium [26] \\
K. liaoningense [21] \\
K. multinerve [15] \\
K. paradoxum [27] \\
K. roycrowsoni [8] \\
K. sharovi [15] \\
K. turutanovae [13] \\
*Kalligramma sp. \\
Kalligrammina [16] \\
K. areolata [16] \\
Limnogramma [20] \\
L. hani [19] \\
L. mira [20] \\
L. mongolicum [19] \\
Sinokalligramma [25] \\
S. jurassicum [25] \\
S.
\end{tabular}

Subfamily Kalligrammatinae Handlirsch, 1906

Angarogramma [28]

A. incertum [28]

$J_{2} / \mathrm{Uda} \mathrm{Fm}$

K. brachyrhyncha sp. nov.

Inner Mongolia, China

$\mathrm{J}_{2} /$ Jiulongshan Fm.

Inner Mongolia, China

$\mathrm{J}_{2} /$ Jiulongshan Fm.

Karatau, Kazakhstan

$J_{3} /$ Karabastau Fm.

Solnhofen, Germany

$J_{3} /$ Solnhofen Fm.

Liaoning, China

$\mathrm{J}_{2} /$ Haifanggou Fm.

Beipiao City, China

$\mathrm{K}_{1}$ /Yixian Fm.

Karatau, Kazakhstan

$\mathrm{J}_{3} /$ Karabastau Fm.

Inner Mongolia, China

$\mathrm{J}_{2}$ /Jiulongshan Fm.

Quarry Hill, England

Karatau, Kazakhstan

$\mathrm{K}_{1}$ /Wadhurst Clay Fm.

$J_{3} /$ Karabastau Fm.

Kazakhstan

$\mathrm{J}_{3} /$ Karabastau Fm.

Inner Mongolia, China

$\mathrm{J}_{2} /$ Jiulongshan Fm.

Karatau, Kazakhstan

$J_{3} /$ Karabastau Fm.

Inner Mongolia, China

$\mathrm{J}_{2}$ /Jiulongshan Fm.

Beipiao City, China

$\mathrm{K}_{1} /$ Yixian Fm.

Inner Mongolia, China

$\mathrm{J}_{2} /$ Jiulongshan Fm.

Subfamily Kallihemerobiinae Ren \& Engel, 2008

Inner Mongolia, China

$\mathrm{J}_{2}$ /Jiulongshan Fm.

Affinigramma gen. nov.

A. myrioneura sp. nov.

Inner Mongolia, China

$\mathrm{J}_{2}$ /Jiulongshan Fm.

Apochrysogramma [24]

A. rotundum [24]

Inner Mongolia, China

$\mathrm{J}_{2}$ /Jiulongshan Fm.

Huiyingogramma [27]

H. formosum [27]

Inner Mongolia, China

$\mathrm{J}_{2}$ /Jiulongshan Fm.

Kalligrammula [13]

K. atra [17]

Mongolia

Karatau, Kazakhstan

Solnhofen, Germany

Inner Mongolia, China

Inner Mongolia, China

Inner Mongolia, China

Inner Mongolia, China

Karatau, Kazakhstan

Inner Mongolia, China
$\mathrm{K}_{1}$ /Shine-Khuduk Fm.

$J_{3} /$ Karabastau Fm.

$\mathrm{J}_{3} /$ Solnhofen Fm.

$\mathrm{J}_{2} /$ Jiulongshan Fm.

$\mathrm{J}_{2} /$ Jiulongshan Fm.

$\mathrm{J}_{2} /$ Jiulongshan Fm.

$\mathrm{J}_{2}$ /Jiulongshan Fm.

$\mathrm{J}_{3} /$ Karabastau Fm.

$\mathrm{J}_{2}$ /Jiulongshan Fm. 
Subfamily Meioneurinae subfam. nov.

Meioneurites [4]
M. schlosseri [4]
M. spectabilis [11]
M. villosus [15]

Subfamily Oregrammatinae subfam. nov.

Abrigramma gen. nov.

A. calophleba sp. nov.

Ithigramma gen. nov.

I. multinervia sp. nov.

*/thigramma sp.

Oregramma [20]

O. aureolusa sp. nov.

O. gloriosa [20]

O. illecebrosa sp. nov.

*Oregramma sp.

Subfamily Sophogrammatinae subfam. nov.

Protokalligramma [24]

P. bifasciatum [24]

Sophogramma [21]

S. eucallum [21]

S. lii [23]

S. papilionacea [21]

S. pingquanica sp. nov.

S. plecophlebia [21]

*Sophogramma sp. [12]

Uncertain subfamily

Palparites [4]

P. deichmuelleri [4]

\author{
Solnhofen, Germany \\ Karatau, Kazakhstan \\ Karatau, Kazakhstan
}

$J_{3} /$ Solnhofen Fm.
$J_{3} /$ Karabastau Fm.
$J_{3} /$ Karabastau Fm.

Pingquan, Hebei, China

$\mathrm{K}_{1}$ /Yixian Fm.

Inner Mongolia, China

$\mathrm{K}_{1} /$ Yixian Fm.

Inner Mongolia, China

$\mathrm{K}_{1}$ /Yixian Fm.

Inner Mongolia, China

Beipiao City, China

Beipiao City, China

Inner Mongolia, China

$\mathrm{K}_{1}$ /Yixian Fm.

$\mathrm{K}_{1} /$ Yixian Fm.

$\mathrm{K}_{1}$ /Yixian Fm.

$\mathrm{K}_{1}$ /Yixian Fm.

Inner Mongolia, China

$\mathrm{J}_{2} /$ Jiulongshan Fm.

Beipiao City, China

$\mathrm{K}_{1}$ /Yixian Fm.

Beipiao City, China

$\mathrm{K}_{1}$ /Yixian Fm.

Beipiao City, China

$\mathrm{K}_{1}$ /Yixian Fm.

Pingquan, Hebei, China

$\mathrm{K}_{1}$ /Yixian Fm.

Beipiao City, China

$\mathrm{K}_{1}$ /Yixian Fm.

Baissa, Russia

$\mathrm{K}_{1} /$ Zaza Fm.

${ }^{1}$ Abbreviations: *Designates an uncertain species; $\mathrm{J}_{2}$, Middle Jurassic, $\mathrm{J}_{3}$, Late Jurassic, $\mathrm{K}_{1}$, Early Cretaceous.

species erected by early systematists and assigned to the Kalligrammatidae were poorly described and based solely on fragmentary wings. There are conflicting relationships among genera and species within the family. For example, the monotypic genus Palparites was erected by [4] based on a poorly preserved specimen and an obfuscating description. Lambkin [6] reassigned the specimen to the Kalligrammatidae, and mentioned that the specimen shares general characters with other kalligrammatids, such as a large body size and a dense network of crossveins. However, the systematic position of this genus within the Kalligrammatidae remains uncertain. Because of the rarity and quality of specimens, it has been difficult to conduct a comprehensive review of this family.

Recently, a large number of well-preserved kalligrammatid specimens have been described from the Mesozoic of China [19-27], augmenting our knowledge of the family. Here, we describe sixteen additional species, including three unassigned to a species and one unassigned to a genus from northeastern China ranging in age from late Middle Jurassic (Jiulongshan Formation, $165 \mathrm{Ma}$ ) to the mid Early Cretaceous (Yixian Formation, $125 \mathrm{Ma}$ ). We redefine the family based on synapomorphic characters, and present a dichotomous key and classification of the genera. We conducted a phylogenetic analysis, and the results partition the Kalligrammatidae into five subfamilies: Kalligrammatinae Handlirsch, 1906 [4], Kallihemerobiinae Ren and Engel [29], Meioneurinae subfam. nov., Oregrammatinae subfam. nov. and Sophogrammatinae subfam. nov. Our goal is to explore the relationships of various extinct kalligrammatid taxa, using a broad sample of well-described material. Our 
study emphasizes the late Middle Jurassic of Daohugou, Inner Mongolia Autonomous Region in northeastern China (Jiulongshan Fm.), the mid Late Jurassic of Karatau, from southern Kazakhstan (Karabastau Fm.), and the mid Early Cretaceous of Liaoning and Hebei Provinces in northeastern China (Yixian Fm.). The Kalligrammatidae exhibit an elevated speciosity and broad morphological diversity during the mid-Mesozoic, suggesting these large insects were a significant ecologic component within the ecosystems they inhabited.

\section{Results}

\section{Descriptions of specimens}

The authors for the new taxa established below shall be Yang, Wang, Labandeira, Shih and Ren.

Wing nomenclature and abbreviations used in the text are as follows: $1 \mathrm{~A}-3 \mathrm{~A}$, anal veins; $\mathrm{C}$, costa; $\mathrm{Cu}$, cubitus; $\mathrm{CuA}$, anterior cubitus; $\mathrm{CuP}$, posterior cubitus; $\mathrm{M}$, media; MA, anterior branch of media; MP, posterior branch of media; ORB, oblique radial branch of anterior radial trace = "radial sector"; pt, pterostigma; $\mathrm{R}$, radius; $\mathrm{R} 1$, first branch of radius; Rs, radial sector; Sc, subcosta; Vr, humeral recurrent vein [30-32].

Order Neuroptera Linnaeus, 1758

Family Kalligrammatidae Handlirsch, 1906

Type genus: Kalligramma Walther, 1904

\section{Redescription}

Large insects (body length more than $50 \mathrm{~mm}$ ); densely setose throughout the body and wings. Antennae filiform, usually not exceeding the length of forewing. Mouthparts mandibulate, or more commonly siphonate and forming a prominent proboscis from conjoined maxillary galeae. Forewing exceptionally large and broad, more than $50 \mathrm{~mm}$ long, approximately triangular or oviform in outline; usually bearing distinct, prominent eyespots positioned in the centers of the wing. Costal region expanded, costal veinlets dichotomously branched distally (with the exception of the Oregrammatinae), interlinked by numerous smaller veinlets. Sc and R1 fused distally; r1-rs crossveins numerous; the basal stem of Rs and R1 usually fused, with the exception of Affinigramma gen. nov., Apochrysogramma and Kallihemerobius where the separation of Rs from R1 is distal from wing base. MA typically originating from Rs as in most neuropterans, except for Affinigramma gen. nov. and Kallihemerobius, with MA diverging from R1; ORB diverging from R1, forming a few pectinate branches, present in some genera of subfamily Kallihemerobiinae; MP extensively branched, $\mathrm{MP}_{2}$ with many distal pectinate branches, consisting of an expansive, triangular region, regarded as an autapomorphy of Kalligrammatidae (except for Sophogramma). Cu forked near wing base; $\mathrm{CuA}$ and $\mathrm{CuP}$ forming complex secondary branches. Anal region broad; 1A parallel to the posterior margin, with complexly bifurcating branches. Hind wing generally triangular; costal veinlets typically simple or with few distal bifurcations.

\section{Remarks}

The extinct family Kalligrammatidae is characterized by remarkably large body size, extremely broad wing shape, unusually dense venation and complex secondary branches of longitudinal veins, which allow separation from other families by their branching pattern. In general, specimens of Kalligrammatidae are poorly preserved with overlapping, incomplete or fragmentary wings. Some species historically were poorly described, resulting in an incomplete understanding of the morphological breadth within the family. The exact definition of the family is imprecise because of the allocation of taxa to varied groups and poor descriptions of many species. One example is the genus Angarogramma, erected by Ponomarenko in 1984, although the venation in the published drawing is overly simplified to provide useful information [28], the specimen still could be attributed to the Kalligrammatidae from the distinctive wing shape. But its generic status is doubtful, as it lacks valid diagnostic characters. For this reason, we propose the above diagnosis of the Kalligrammatidae for unambiguous differentiation of this family from other families of Neuroptera.

Subfamily Kallihemerobiinae Ren \& Engel, 2008

Type genus. Kallihemerobius Ren \& Oswald, 2002.

Included genera. Type genus and Affinigramma gen. nov., Apochrysogramma Yang, Makarkin \& Ren, 2011, Huiyingogramma Liu et al., 2013, Kalligrammula Martynova, 1947, Lithogramma Panfilov, 1968, and Stelligramma gen. nov.

\section{Diagnosis}

No convincing characters uniquely define the Kallihemerobiinae. However, the parsimony analysis below indicates that the deep MA bifurcation indicates monophyly of the Kallihemerobiinae. However, establishment of robust characters for the Kallihemerobiinae monophyly requires further testing with additional specimens and data.

Genus Affinigramma gen. nov.

(urn:Isid:zoobank.org:act:4221DD6B-A562-4CC0-BBD8D89F292D8815)

Type species. Affinigramma myrioneura sp. nov.

\section{Etymology}

The generic name is derived from the Latin word affinis, meaning "similar" or "related", and the Greek gramma, meaning "lined" or "written", referring to wings that resemble a manuscript, also a common suffix for kalligrammatid genera. Gender feminine. 


\section{Diagnosis}

Siphonate proboscis present. Humeral recurrent veins $(\mathrm{Vr})$ absent; all costal veinlets sinuate and forked. Rs with at least 6 pectinately forked branches. Only one, the ORB, between Rs and MA. MA originating from $\mathrm{R} 1$, initially dichotomously forked, then pectinately forked and continuing to vein end. $\mathrm{CuA}$ single; $\mathrm{CuP}$ pectinately forked. 1A pectinately forked.

\section{Remarks}

Affinigramma myrioneura gen. et sp. nov. is placed in the subfamily Kallihemerobiinae by having the following characters: 1), the longitudinal veins bear marginal branching along the wing margin; 2), crossveins are not present in the area of marginal branching; 3), the forewing has forked c-sc crossveins; and 4), the Sc terminates in the R1 near the wing apex. The new genus differs from Kallihemerobius [22] in the following characters: 1), all costal veinlets are sinuate and bear a sparsely branched, humeral recurrent crossvein; 2), the Rs is branched from the R1 only, but not with multiple "Rs" veins as in Kallihemerobius; 3 ), only one pectinately forked ORB is present; 4), the MA branches separately from the $\mathrm{R} 1 ; 5)$, the $\mathrm{CuA}$ is single; and 6), all anal veins are pectinately forked.

Affinigramma myrioneura sp. nov. (Figure 1)

(urn:lsid:zoobank.org:act:344C60A3-F25E-4FB6-A2E832B17A2653C7)

Diagnosis. As for the genus, by monotypy.

\section{Etymology}

The specific epithet of myrioneura is derived from the Greek words myrio, meaning "countless" or "numberless", and neura, meaning a "sinew" or "nerve", referring to the complex venation of this species.

\section{Holotype}

Specimen (part and counterpart) with partial body and one forewing; specimen CNU-NEU-NN2009-006P/C (Figure 1A, B). Paratype with four, superimposed wings; wellpreserved head and leg segments (part and counterpart); specimen CNU-NEU-NN2009-007P/C (Figure 1D-F). The sex is unknown for both specimens.

\section{Type locality and horizon}

Jiulongshan Formation, Middle Jurassic; Daohugou Village, Shantou Township, Ningcheng County, Inner Mongolia, China.

\section{Measurements}

Holotype, CNU-NEU-NN2009-006P/C (Figure 1A, B): forewing ca. $62 \mathrm{~mm}$ long, $40 \mathrm{~mm}$ wide. Paratype, CNUNEU-NN2009-007P/C (Figure 1D, E): forewing ca. $68 \mathrm{~mm}$ long, $35 \mathrm{~mm}$ wide as preserved.

\section{Description}

Large insects, body partly preserved in lateral view (Figure 1C); forewing nearly complete. Head elongate; antennae not preserved. Siphonate proboscis present. Legs partially preserved; structure unclear. Dense crossveins throughout the wings. Forewing broadly ovoidal in shape, with rounded apex. Humeral recurrent veins $(\mathrm{Vr})$ absent, all costal veinlets sinuate and forked. R1 simple, parallel to Sc for a long distance, fused apically, and then curved posteriorly to enter margin before wing apex; Rs with ca. 6 primary branches, all pectinately forked. Only one ORB between Rs and MA, with ca. three pectinate branches. MA originating from R1, initially dichotomously forked, then pectinately forked distally; MP sinuate, with at least 6 branches, the first simple, the others pectinately forked. $\mathrm{CuA}$ single; $\mathrm{CuP}$ pectinately forked, with more than 4 branches. Between $\mathrm{CuA}$ and $\mathrm{CuP}$ an intercalary vein originates from $\mathrm{CuP}$ and ends at $\mathrm{CuP}$ prior to branching. 1A with many pectinately forked branches; 2A and 3A simple, all pectinately forked. Wing eyespot obvious on forewing.

Genus Kallihemerobius Ren \& Oswald, 2002

Type species. Kallihemerobius pleioneurus Ren \& Oswald, 2002

Included species. Type species and Kallihemerobius aciedentatus sp. nov., Kallihemerobius almacellus sp. nov., and Kallihemerobius feroculus sp. nov.

Kallihemerobius aciedentatus sp. nov. (Figure 2)

(urn:lsid:zoobank.org:act:3554140B-1919-49D8-BC31E3248D5A8E10)

\section{Diagnosis}

Mouthparts siphonate. Forewing with 8 ORB between Rs and MA; MP with 9 pectinate branches, the second pectinately forked. Hind wing with $8 \mathrm{ORB}$, all dichotomously forked; MA with 3 pectinate branches.

\section{Etymology}

The specific epithet, aciedentatus, comes from the Latin acies, meaning "sharp" or "edge", and dentatus, meaning "tooth-like" or "having teeth".

\section{Holotype}

Specimen (part and counterpart) with partial body and four wings, specimen CNU-NEU-NN2010-008P/C (Figure 2A, B). Sex unknown.

\section{Type locality and horizon}

Jiulongshan Formation, Middle Jurassic, Daohugou Village, Shantou Township, Ningcheng County, Inner Mongolia, China. 


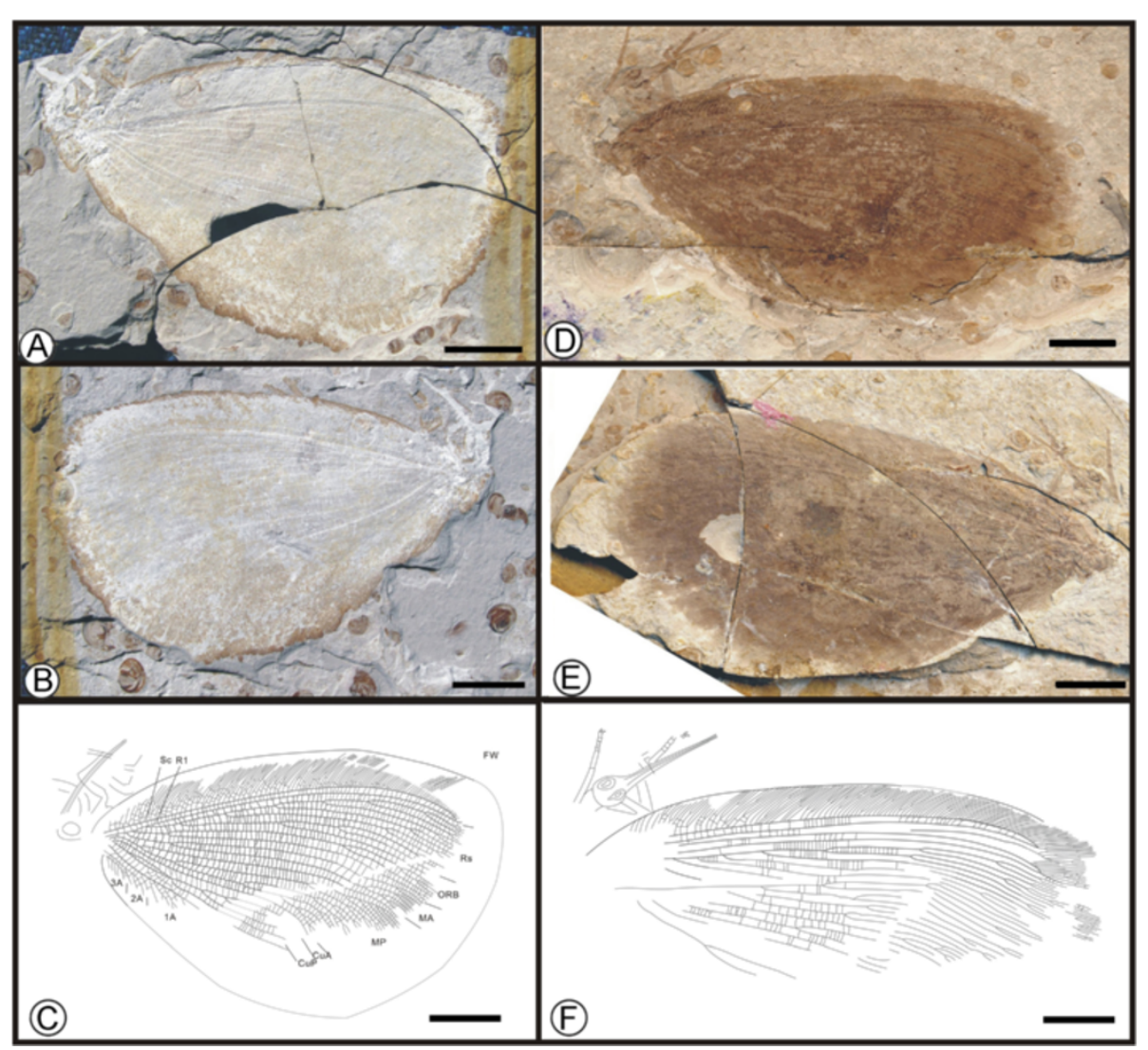

Figure 1 Images and camera lucida drawings of Affinigramma myrioneura sp. nov. A, B, C, Holotype CNU-NEU-NN2009-006P/C; D, E, F, Paratype CNU-NEU-NN2009-007P/C. Scale bars, $10 \mathrm{~mm}$.

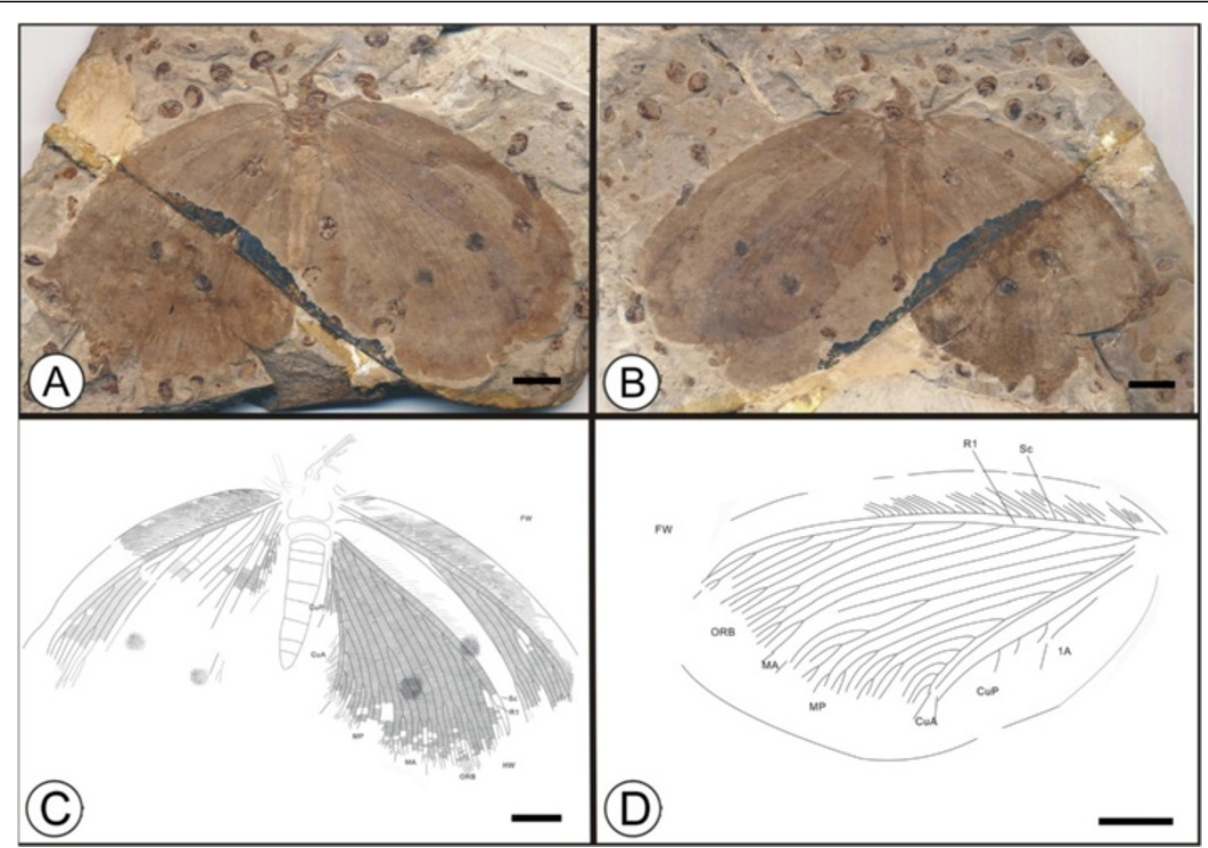

Figure 2 Images and camera lucida drawings of Kallihemerobius aciedentatus sp. nov. CNU-NEU-NN2010-008P/C; A, B, Holotype; C, Outline of holotype; D, Outline of forewing. Scale bars, $10 \mathrm{~mm}$. 


\section{Measurements}

Holotype, CNU-NEU-NN2010-008P/C (Figure 2A, B): forewing $67 \mathrm{~mm}$ long and $32 \mathrm{~mm}$ wide as preserved; hind wing ca. $61 \mathrm{~mm}$ long, $38 \mathrm{~mm}$ wide as preserved.

\section{Description}

Head elongate; antennae filiform, one preserving nine articles (Figure 2C); compound eye large, occupying ca. half of head length; malar space elongate. Proboscis complete, galeae disassociated. Legs partly preserved. Abdomen covered by hind wing, poorly preserved.

Forewing oviform (Figure 2D) Dense crossveins throughout the wing. Humeral recurrent veins $(\mathrm{Vr})$ absent, all costal veinlets sinuate and deeply forked. R1 simple, parallel to Sc for a long distance and fused apically; 8 ORB between Rs and MA, all dichotomously forked. MA originating from R1, simple; MP sinuate, with 9 pectinate branches. CuP with several pectinate branches. Wing spot obvious on forewing, consisting of one black, circular splotch.

Hind wing oviform. Humeral recurrent veins $(\mathrm{Vr})$ absent; all costal veinlets sinuate and deeply dichotomously forked. R1 simple, parallel to Sc for a substantial distance and fused apically, then curved posteriorly toward the wing margin; Rs bifurcate in the preserved part, with 8 ORB all dichotomously forked. MA originating from R1, forked at vein midsection, with 3 pectinate branches; MP sinuate, with at least 7 outwardly directed pectinate branches, the first simple, the others dichotomously forked. $\mathrm{CuA}$ with at least 10 pectinate branches; $\mathrm{CuP}$ not clear. A not preserved.

\section{Remarks}

Kallihemerobius aciedentatus sp. nov. is one of the bestpreserved specimens examined, with four wings extended and detailed body structures present. It differs from other species in the following characters: 1), the siphonate proboscis and palpi are long and narrow; 2), the forewing Rs has eight ORB, all dichotomously forked; 3 ), the forewing $\mathrm{MP}$ vein bears nine pectinate branches, the second pectinately forked; 4), the hind wing Rs vein has eight ORB, all dichotomously forked; and 5), the hind wing MA vein subtends three pectinate branches.

Kallihemerobius almacellus sp. nov. (Figure 3)

(urn:lsid:zoobank.org:act:3628F2E7-7898-46E6-97 F2D07AD9E00CD5)

\section{Diagnosis}

Head with substantial malar space; siphonate proboscis present. Hind wing lacking humeral recurrent veins $(\mathrm{Vr})$. Rs bearing at least 3 pectinate branches; 7 ORBs between Rs and MA. MP sinuate, comprising 9 branches, the first simple, the second with 4 pectinately forked branches, the others dichotomously forked. CuA with at least 13 pectinate branches. Wing eyespot conspicuous.

\section{Etymology}

The specific epithet, almacellus, is derived from the Latin alma, meaning "nourishing" or "kind", and cella, meaning "a cell" or "a small enclosure", referring to the abundant cells within the wings.

\section{Holotype}

Specimen (part and counterpart) with partial body and one hind wing; specimen CNU-NEU-NN2009-050P/C (Figure 3A, B). Sex unknown.

\section{Type locality and horizon}

Jiulongshan Formation, Middle Jurassic, Daohugou Village, Shantou Township, Ningcheng County, Inner Mongolia, China.

\section{Measurements}

Holotype, CNU-NEU-NN2009-050P/C (Figure 3A, B): hind wing ca. $46 \mathrm{~mm}$ long, $30 \mathrm{~mm}$ wide as preserved.

\section{Description}

Head elongate, small (Figure 3C); antennae not preserved; compound eyes large, occupying ca. half of head length; malar space significant. Siphonate proboscis, with overlapping maxillary palps. Leg elements variably preserved. Hind wing well preserved. Wing eyespot obvious. Hind wing oviform. Humeral recurrent veins (Vr) absent; all costal veinlets sinuate and deeply dichotomously forked. R1 simple, parallel to Sc for a long distance and fused apically, then curved posteriorly toward wing margin; Rs comprised of at least 3 pectinate branches; 7 ORBs between Rs and MA; $\mathrm{ORB}_{2}$ forked much earlier than others. MA originating from R1, forked near wing base, with two dichotomously forked branches; MP sinuate, with 9 branches, the first simple, the second with 4 pectinately forked branches, the others dichotomously forked. $\mathrm{CuA}$ with at least 13 pectinate branches; $\mathrm{CuP}$ not clear. A veins not preserved.

\section{Remarks}

Kallihemerobius almacellus sp. nov. differs from other species in the following characters: 1 ), the costal region is broader; 2), seven ORBs are present; 3), the second branch of MP is pectinately forked; and 4), the CuA subtends at least thirteen pectinate branches.

Kallihemerobius feroculus sp. nov. (Figure 4)

(urn:lsid:zoobank.org:act:1D58ECE7-DE1F-46FB-B8691E3B0455FF79)

\section{Diagnosis}

Forewing bearing humeral recurrent veins $(\mathrm{Vr})$ and 5 ORBs; $\mathrm{ORB}_{3}$ forked earlier than others. MA forked nearly $1 / 3$ the distance from the wing base; MP sinuate, the second branch with ca. 6 pectinate branches, 


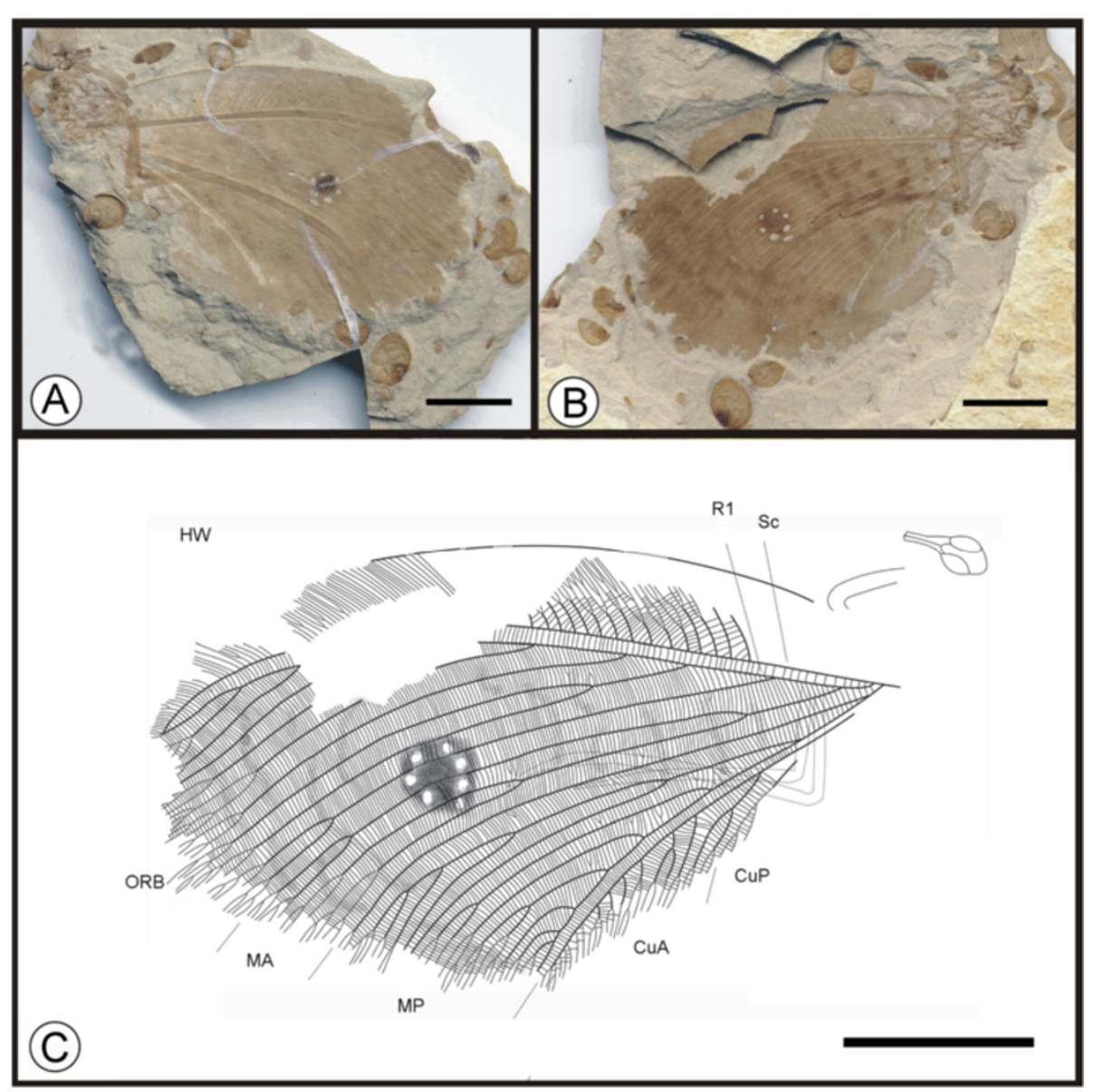

Figure 3 Images and camera lucida drawing of Kallihemerobius almacellus sp. nov. CNU-NEU-NN2009-050P/C. A, B, Holotype; C, Outline of holotype. Scale bars, $10 \mathrm{~mm}$.

the others dichotomously forked. $\mathrm{CuA}$ and $\mathrm{CuP}$ pectinately forked. 1A and 2A pectinately forked. Wing eyespot prominent; a central, dark pigmented area surrounded by a ring.

\section{Etymology}

The specific epithet, feroculus, is from the diminutive Latin Word, feroculus, meaning "fierce" or "savage".

\section{Holotype}

A specimen (part and counterpart) with partial body and one forewing; specimen CNU-NEU-NN2010-013P/C (Figure 4A, B). Sex unknown.

\section{Type locality and horizon}

Jiulongshan Formation, Middle Jurassic, Daohugou Village, Shantou Township, Ningcheng County, Inner Mongolia, China.

\section{Measurements}

Holotype, CNU-NEU-NN2010-013P/C (Figure 4A, B): forewing ca. $37 \mathrm{~mm}$ long, $26 \mathrm{~mm}$ wide as preserved.

\section{Description}

A well-preserved forewing with a missing border. Body partially preserved. Head and mouthparts preserved ventrally (Figure 4C).

Forewing oviform. Humeral recurrent veins $(\mathrm{Vr})$ present, all costal veinlets sinuate and deeply forked. R1 simple, parallel to Sc for a significant distance and fused apically; Rs simple in preserved part; 5 ORBs, $\mathrm{ORB}_{3}$ with 6 primary pectinate branches, all dichotomously forked; $\mathrm{Rs}_{3}$ forked earlier than others. MA originating from R1, forked nearly $1 / 3$ the distance from wing base, with 3 pectinate branches, each dichotomously forked; MP sinuate, with 5 pectinate branches, the second with ca. 6 pectinate branches, the others dichotomously forked. CuA pectinately forked near wing margin; $\mathrm{CuP}$ with ca. 10 pectinate branches. $1 \mathrm{~A}$ and $2 \mathrm{~A}$ parallel to $\mathrm{CuP}$ and pectinately forked; $3 \mathrm{~A}$ absent or not preserved. Wing eyespot obvious, enveloped by a circular ring.

\section{Remarks}

Kallihemerobius feroculus sp. nov. differs from other species in the following characters: 1), only five ORBs are present; 


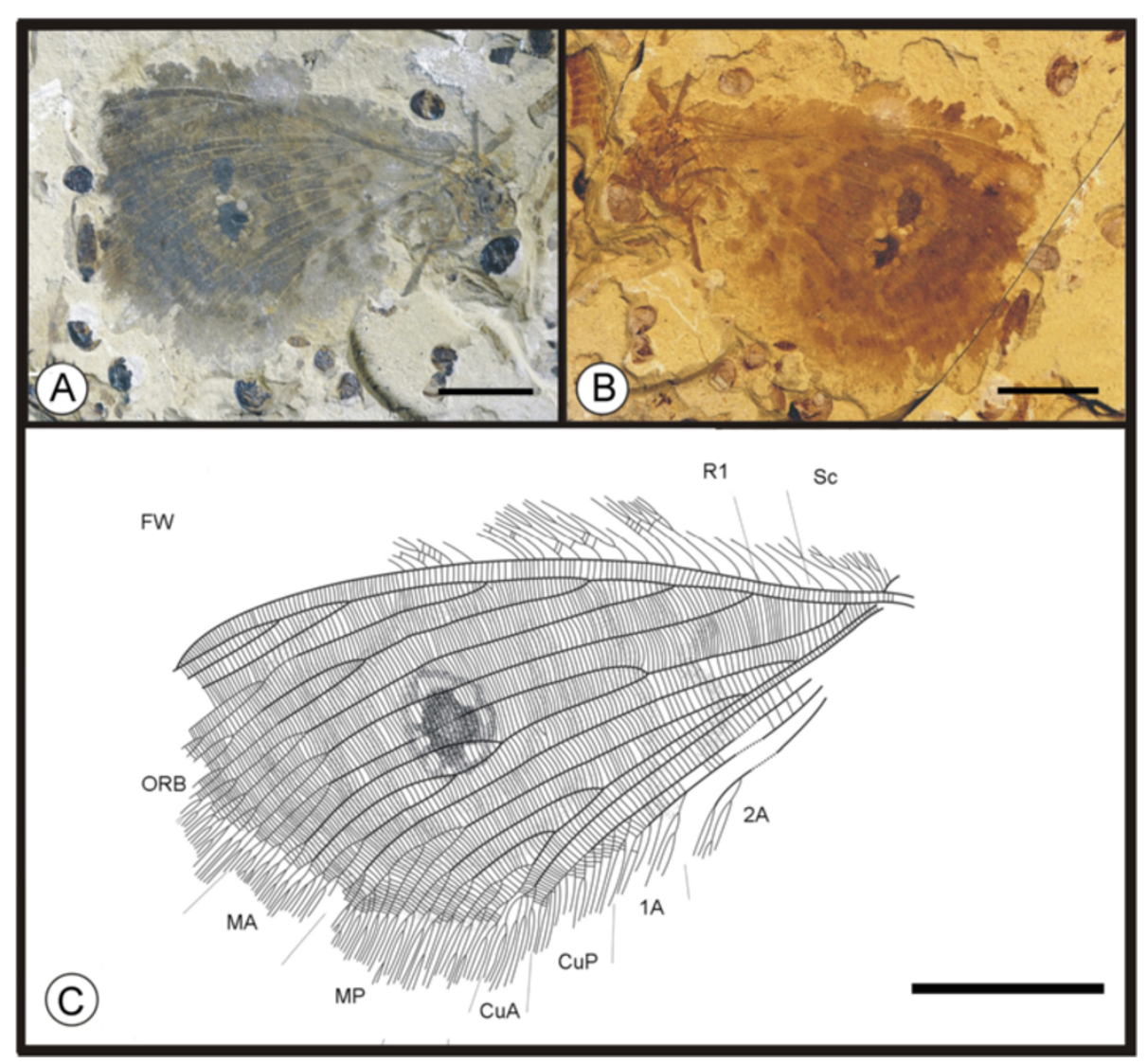

Figure 4 Images and camera lucida drawing of Kallihemerobius feroculus sp. nov. CNU-NEU-NN2010-013P/C. A, B, Holotype; C, Outline of holotype. Scale bars, $10 \mathrm{~mm}$.

2), the MA is forked considerably earlier; 3), the MP subtends five pectinate branches; 4 ), the $\mathrm{CuA}$ is pectinately forked near the wing margin; 5), the $\mathrm{CuP}$ has ca. ten pectinate branches; and 6 ), the $1 \mathrm{~A}$ and $2 \mathrm{~A}$ veins are pectinately forked.

Genus Stelligramma gen. nov.

(urn:lsid:zoobank.org:act:D4606681-1755-422 F-BDE9A94F4C97B43F)

Type species. Stelligramma allochroma sp. nov.

\section{Etymology}

The generic name is derived from the Latin stella, meaning "star" or "astral", and the Greek gramma, meaning "lined" or "written", referring to wings resembling a manuscript; also a common suffix for kalligrammatid genera. Gender feminine.

\section{Diagnosis}

Forewing without eyespot markings. Humeral recurrent veins ( $\mathrm{Vr}$ ) evident. Most costal veinlets curved, deeply forked near wing margin, bearing one to three interlinked veinlets. Rs with pectinate branches, all bifurcate. MA forked at vein midsection. $\mathrm{Cu}$ forked into two branches at wing base; $\mathrm{CuA}$ pectinately forked terminally and $\mathrm{CuP}$ dichotomously forked at midvein. 1A deeply dichotomously forked; 2A pectinately forked, each branch dichotomously forked; 3A simple.

\section{Remarks}

The genus Stelligramma gen. nov. has a common kalligrammatid-like appearance, and was assigned to the subfamily Kallihemerobiinae. The kallihemerobiine assemblage is complex for its varied wing structure, including the absence of the ORB, and narrow costal region. Based on our phylogenetic analysis, the monophyly of subfamily Kallihemerobiinae is supported by a single character: proximal forking of the 1A vein. Stelligramma gen. nov. and Kalligrammula constitute the stem-group of Kallihemerobiinae, representing the earliest divergence of the subfamily. This divergence implies that absence of the ORB among Stelligramma gen. nov. and Kalligrammula is likely an ancestral feature.

Stelligramma allochroma sp. nov. (Figure 5)

(urn:lsid:zoobank.org:act:910C978D-F8C3-4D26-B9DDBC627FDB8A35)

Diagnosis. As for the genus, by monotypy. 


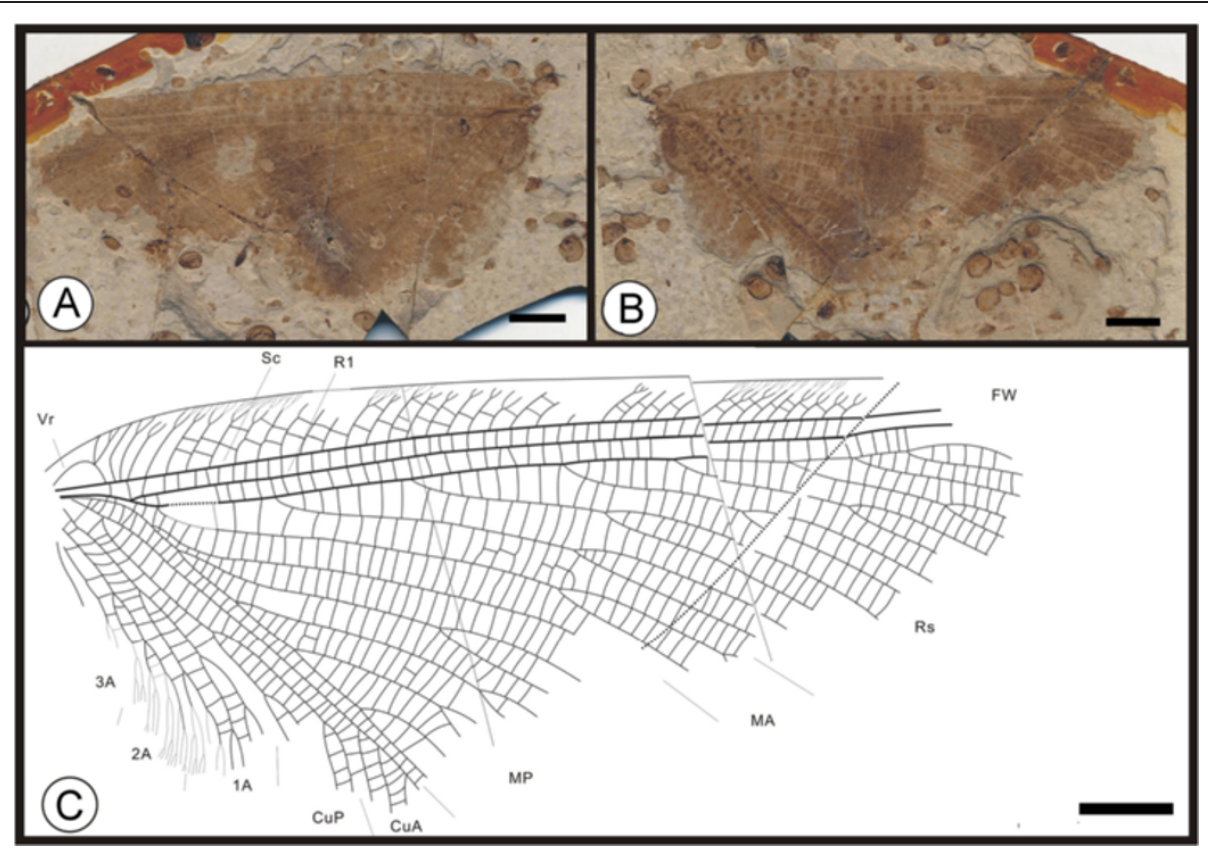

Figure 5 Images and camera lucida drawing of Stelligramma allochroma sp. nov. CNU-NEU-NN2010-012P/C. A, B, Holotype; C, Outline of holotype. Scale bars, $10 \mathrm{~mm}$.

\section{Etymology}

The epithet of allochroma is derived from the Greek words, allos, meaning "other" or "different", and chroma, meaning "color" or "hue".

\section{Holotype}

A well-preserved forewing (part and counterpart); specimen CNU-NEU-NN2010-012P/C (Figure 5A, B). Sex unknown.

\section{Type locality and horizon}

Jiulongshan Formation, Middle Jurassic, Daohugou Village, Shantou Township, Ningcheng County, Inner Mongolia, China.

\section{Measurements}

Holotype, CNU-NEU-NN2010-012P/C (Figure 5A,B): forewing ca. $90 \mathrm{~mm}$ long, $44 \mathrm{~mm}$ wide.

\section{Description}

One partially preserved forewing (Figure 5C). Axial body not preserved. Forewing approximately obtuse-triangular. Eyespot or spot absent. Humeral recurrent veins (Vr) evident. Most costal veinlets curved and deeply forked at wing margin, between which are one or two interlinked veinlets. R1 parallel to Sc where preserved. Rs with more than 7 original branches, all bifurcate. MA forked at vein midsection; MP forked near wing base, with at least 5 pectinate branches, the first simple, the others dichotomously forked. $\mathrm{Cu}$ forked into two branches at wing base; $\mathrm{CuA}$ parallel with MP and pectinately forked at end; $\mathrm{CuP}$ dichotomously forked at vein midsection. 1A forked earlier than $\mathrm{CuP}$, deeply dichotomously forked; 2A with ca. 3 pectinate branches, each dichotomously forked; $3 \mathrm{~A}$ simple. Wing spot obvious on forewing, consisting of one black, circular splotch.

Kallihemerobiinae gen. et sp. indet. (Figure 6)

\section{Material}

A mostly poorly preserved specimen with partial body and wing impression; specimen CNU-NEU-NN2009-033 (Figure 6A). Sex unknown.

\section{Type locality and horizon}

Jiulongshan Formation, Middle Jurassic, Daohugou Village, Shantou Township, Ningcheng County, Inner Mongolia, China.

\section{Description}

Body preserved in ventral view (Figure 6B). Head better preserved; compound eyes hemispheroidal, modest; proboscis present, with maxillary palps; antenna filiform, only left antenna (partly) preserved. Legs incompletely preserved. Dense crossveins throughout the wings. Forewing costal region broad; all costal veinlets sinuate, deeply forked; other structures indistinct. Forewing spot or eyespot absent.

\section{Remarks}

The presence of a siphonate proboscis and an ORB suggests that this specimen unequivocally belongs to 


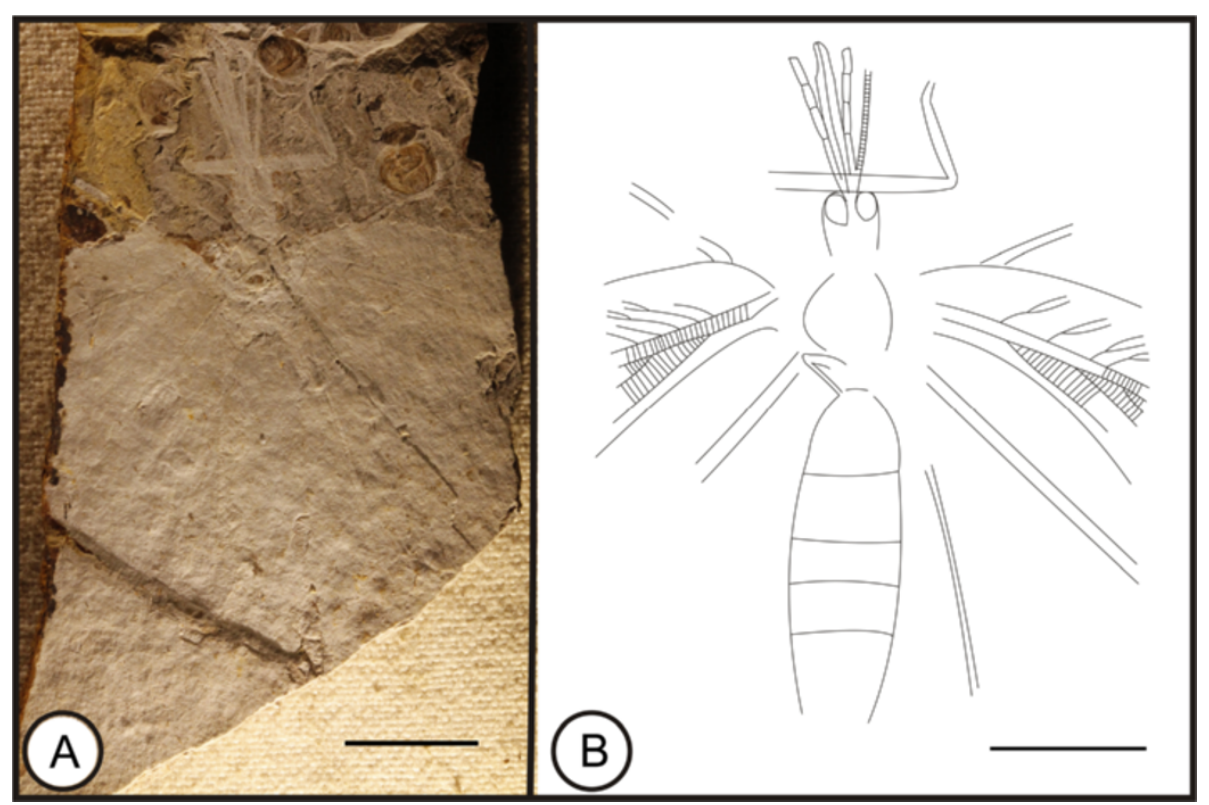

Figure 6 Image and camera lucida drawings of Kallihemerobiinae gen. et sp. indet. CNU-NEU-NN2009-033. A, Habitus; B, Outline of habitus. Scale bars, $10 \mathrm{~mm}$.

the Kallihemerobiinae. However, other parts of the specimen are so poorly preserved that they lacks diagnostic information to determine the specimens' generic status. We assign this specimen as gen. et sp. indet. to the Kallihemerobiinae.

Subfamily Kalligrammatinae Handlirsch, 1906

Type genus: Kalligramma Walther, 1904

\section{Included genera}

Type genus and Angarogramma Ponomarenko, 1984; Kalligrammina Panfilov, 1980; Limnogramma Ren, 2003; and Sinokalligramma Zhang, 2003.

\section{Diagnosis}

Apomorphic characters defining the Kalligrammatinae are: 1), distal pectinate branching in the anterior media (MA) vein; 2), complex branching along the distal course of the anterior cubitus (CuA) vein; and 3), complex branching along the distal course of the posterior cubitus $(\mathrm{CuP})$ vein.

\section{Remarks}

The subfamily consists of five genera typical of the Kalligrammatidae. The Kalligrammatinae is distinguished from the other subfamilies by the following characters: 1), a broad triangular MP region versus parallel MP branches among the Sophogrammatinae; 2), absence of an ORB versus presence of an ORB among Kallihemerobiinae; and 3), a complex costal cross-venation versus simple costal cross-venation among Meioneurinae and Oregrammatinae. Although the establishment of the Kalligrammatinae is based on a combination of the above apomorphic characters, this taxon currently lacks a synapomorphy.

Genus Kalligramma Walther, 1904

Type species Kalligramma haeckeli Walther, 1904

\section{Included species}

Type species and Kalligramma brachyrhyncha sp. nov., Kalligramma circularia sp. nov., Kalligramma flexuosum Panfilov, 1968; Kalligramma jurarchegonium J. Zhang \& H. Zhang, 2003, Kalligramma liaoningense Ren \& Guo, 1996, Kalligramma multinerve Panfilov, 1968, Kalligramma roycrowsoni Jarzembowski, 2001, Kalligramma sharovi Panfilov, 1968, Kalligramma turutanovae Martynova, 1947. Kalligramma brachyrhyncha sp. nov.; Kalligramma circularia sp. nov.

Kalligramma brachyrhyncha sp. nov. (Figure 7)

(urn:lsid:zoobank.org:act:620F475B-7CFB-4A32-AD77DC6CBEF3D94C)

\section{Diagnosis}

Most costal veinlets curved and forking multichotomously; interlinked veinlets between costal veinlets abundant. Rs with more than 6 primary branches; MP forked near wing base, with 6 pectinate branches, the first forked later than the second. $\mathrm{Cu}$ divided into $\mathrm{CuA}$ and $\mathrm{CuP}$ near base; one intercalary vein between $\mathrm{Cu}$ and $1 \mathrm{~A}$.

\section{Etymology}

The specific epithet of brachyrhyncha is derived from the Greek words of "brachy", meaning "short" or "abbreviated", and rhynchos, for "beak" or "mouth". 


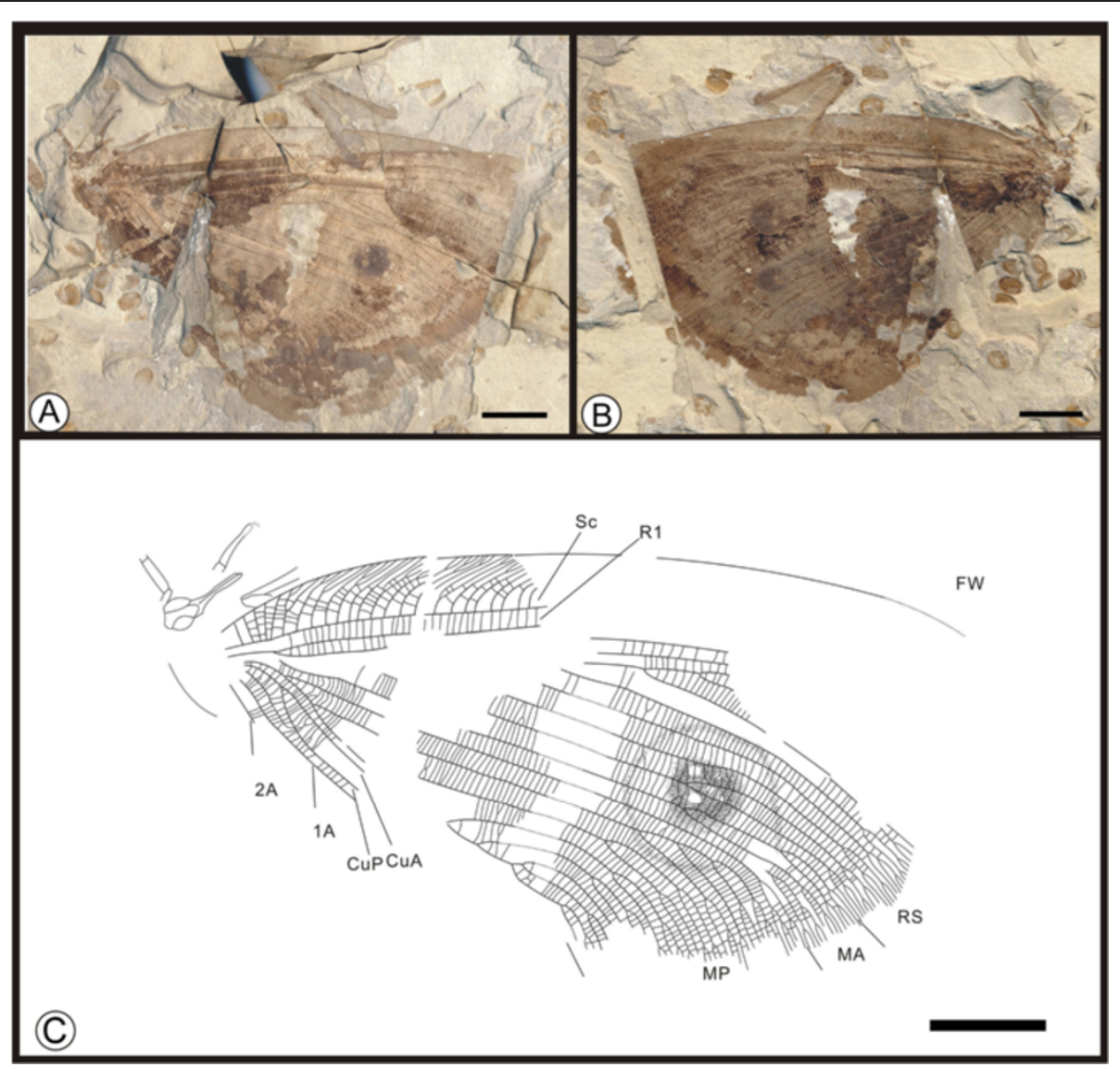

Figure 7 Images and camera lucida drawing of Kalligramma brachyrhyncha sp. nov. CNU-NEU-NN2009-030P/C. A, B, Holotype; C, Outline of holotype. Scale bars, $10 \mathrm{~mm}$.

\section{Holotype}

A partially preserved specimen (part and counterpart) with four overlapping wings and incomplete body; specimen CNU-NEU-NN2009-030P/C (Figure 7A,B). Sex unknown.

\section{Type locality and horizon}

Jiulongshan Formation, Middle Jurassic, Daohugou Village, Shantou Township, Ningcheng County, Inner Mongolia, China.

\section{Measurements}

Holotype, CNU-NEU-NN2009-030P/C (Figure 7A,B): siphonate proboscis present; forewing approximately $73 \mathrm{~mm}$ long, $42 \mathrm{~mm}$ wide; hind wing ca. $71 \mathrm{~mm}$ long, $42 \mathrm{~mm}$ wide.

\section{Description}

Body preserved in lateral view (Figure 7C). Antennae not preserved. Siphonate proboscis shorter than the maxillary palps. Thorax and abdomen poorly preserved. Forewings and hind wings overlapping; most of forewing discernible. Forewing approximately obtuse-triangular. Most costal veinlets curved and forked. Rs with more than 6 primary branches; forked near wing apex. MA with 2 pectinate branches at posterior margin; MP forked close to wing base, with 6 pectinate branches, the first forked later than the second. At the preserved wing base, $\mathrm{Cu}$ divided into $\mathrm{CuA}$ and $\mathrm{CuP}$, and one intercalary vein between $\mathrm{Cu}$ and $1 \mathrm{~A}$. Anal region indistinct; $1 \mathrm{~A}$ simple, as preserved. Wing eyespot obvious on forewing, consisting of light colored ovate ocules within and surrounding the central pigmented area, in turn enveloped by a circular, darkly pigmented ring at some distance. Hind wing broad, nearly acute-triangular; preservation fragmentary, only the overall outline and apical region identifiable. In the preserved part, most costal veinlets curved and forked. Sc and R1 fused apically and then curved posteriorly to enter margin before wing apex, Rs exceeding 5 branches; each sequentially forked.

\section{Remarks}

Kalligramma brachyrhyncha sp. nov. is attributable to the genus Kalligramma based on the above-mentioned characters. Kalligramma brachyrhyncha sp. nov. is similar to K. turutanovae [13] in forewing structure, although $K$. turutanovae is preserved without a hind wing. In the 
new species, the Rs has more than six primary branches, whereas $K$. turutanovae has more than eight. In the new species the MP is forked near the wing base, with six pectinate branches, the first forked later than the second, whereas in $K$. turutanovae the MP has three visible branches, and the first is forked earlier than the second. In the new species, the $\mathrm{Cu}$ is divided into a $\mathrm{CuA}$ and a $\mathrm{CuP}$ near the wing base, and one intercalary vein occurs between the $\mathrm{Cu}$ and $1 \mathrm{~A}$; by contrast, in $K$. turutanovae both the $\mathrm{CuA}$ and $\mathrm{CuP}$ are pectinately forked.

Kalligramma brachyrhyncha sp. nov. resembles $K$. multinerve [15] in forewing features. The new species has most costal veinlets curved, forking multichotomously, and interlinked with all regional veinlets, whereas $K$. multinerve has costal veinlets forked twice, lacking crossveins posteriorly, and Sc and R1 are not fused in the preserved material. In the new species, the MP has six pectinate branches, but in $K$. multinerve the MP has three visible branches. For the new species the $\mathrm{Cu}$ is divided into a $\mathrm{CuA}$ and a $\mathrm{CuP}$ near the wing base, and one intercalary vein occurs between the $\mathrm{Cu}$ and $1 \mathrm{~A}$, but in $K$. multinerve the $\mathrm{CuA}$ is simple.

Kalligramma circularia sp. nov. (Figure 8)

(urn:lsid:zoobank.org:act:01A5669B-7C4C-4 F20-99B0BDE6B98A639B)

\section{Diagnosis}

Forewing costal margin with an obvious structural camber. Most costal veinlets forked, with few interlinked veinlets. Rs with 12 original branches; MP with more than 9 pectinate branches, the second pectinately forked, with 6 branches. Both $\mathrm{CuA}$ and $\mathrm{CuP}$ pectinately forked at the wing margin. 1A pectinately forked.

\section{Etymology}

The specific epithet originates from the Latin "circularis", meaning "circular", "round" or an "orb", emphasizing the large, round wing eyespots of this species.

\section{Holotype}

A partially preserved specimen with four overlapping wings and an incomplete body; specimen CNU-NEU-NN2010003 (Figure 8A). Paratype specimens CNU-NEU-NN2010015P/C (Figure 8C,D) and CNU-NEU-NN2010-011 (Figure $8 \mathrm{~B}$ ). The sex is unknown for all specimens.

\section{Type locality and horizon}

Jiulongshan Formation, Middle Jurassic, Daohugou Village, Shantou Township, Ningcheng County, Inner Mongolia, China.

\section{Measurements}

Holotype, CNU-NEU-NN2010-003 (Figure 8A): forewing ca. $65 \mathrm{~mm}$ long, $54 \mathrm{~mm}$ wide as preserved. Paratypes,
CNU-NEU-NN2010-015P/C (Figure 8C, D): proboscis preserved. CNU-NEU-NN2010-011 (Figure 8B): proboscis present, forewing ca. $87 \mathrm{~mm}$ long, $49 \mathrm{~mm}$ wide.

\section{Description}

Body preserved in lateral view (Figure 8E). Head partially preserved, structures ambiguous; mouthparts not preserved. Compound eyes hemispheroidal and prominent; antennae not preserved. Thorax and abdomen poorly preserved. Femora and tibiae of legs preserved. Forewings and hind wings overlapping, most forewing features discernible; wings with abundant crossveins throughout.

Forewing of holotype approximately obtuse-triangular (Figure 8F). Most costal veinlets curved and forked; few interlinked veinlets. Sc and R1 parallel, fused apically and subsequently curved posteriorly toward the margin. Rs with 12 primary branches, forked at wing apex. MA exceeding 3 pectinate branches; stem of MP, $\mathrm{CuA}$ and $\mathrm{CuP}$ not preserved. Anal region indistinct; $1 \mathrm{~A}$ with many pectinate branches. Wing eyespot obvious. Hind wing preservation fragmentary for the holotype (Figure 8G). Hind wing of paratype CNU-NEU-NN2010011 with relatively narrow costal region (Figure $8 \mathrm{H}$ ); most costal veinlets curved and forked, with several interlinked veinlets. R1 parallel to Sc; Rs with more than 7 pectinate branches. MA originating from a barely discernible R1.

\section{Remarks}

Kalligramma circularia sp. nov. is similar to $K$. multinerve [15] in forewing features, the latter of which is preserved without a hind wing. It is different from $K$. multinerve in the following characters: 1), most of the new species' costal veinlets are forked, with few interlinked veinlets; 2 ), the Rs has 12 primary branches; 3 ), the MP subtends more than nine pectinate branches, the second pectinately forked, with six branches; and 4), both the $\mathrm{CuA}$ and $\mathrm{CuP}$ are pectinately forked at the wing margin.

\section{Kalligramma sp. (Figure 9)}

\section{Material}

A partially preserved specimen with four overlapping wings and incomplete body (part and counterpart); specimen CNU-NEU-NN2010-010P/C (Figure 9A,B). The sex is unknown.

\section{Type locality and horizon}

Jiulongshan Formation, Middle Jurassic, Daohugou Village, Shantou Township, Ningcheng County, Inner Mongolia, China. 


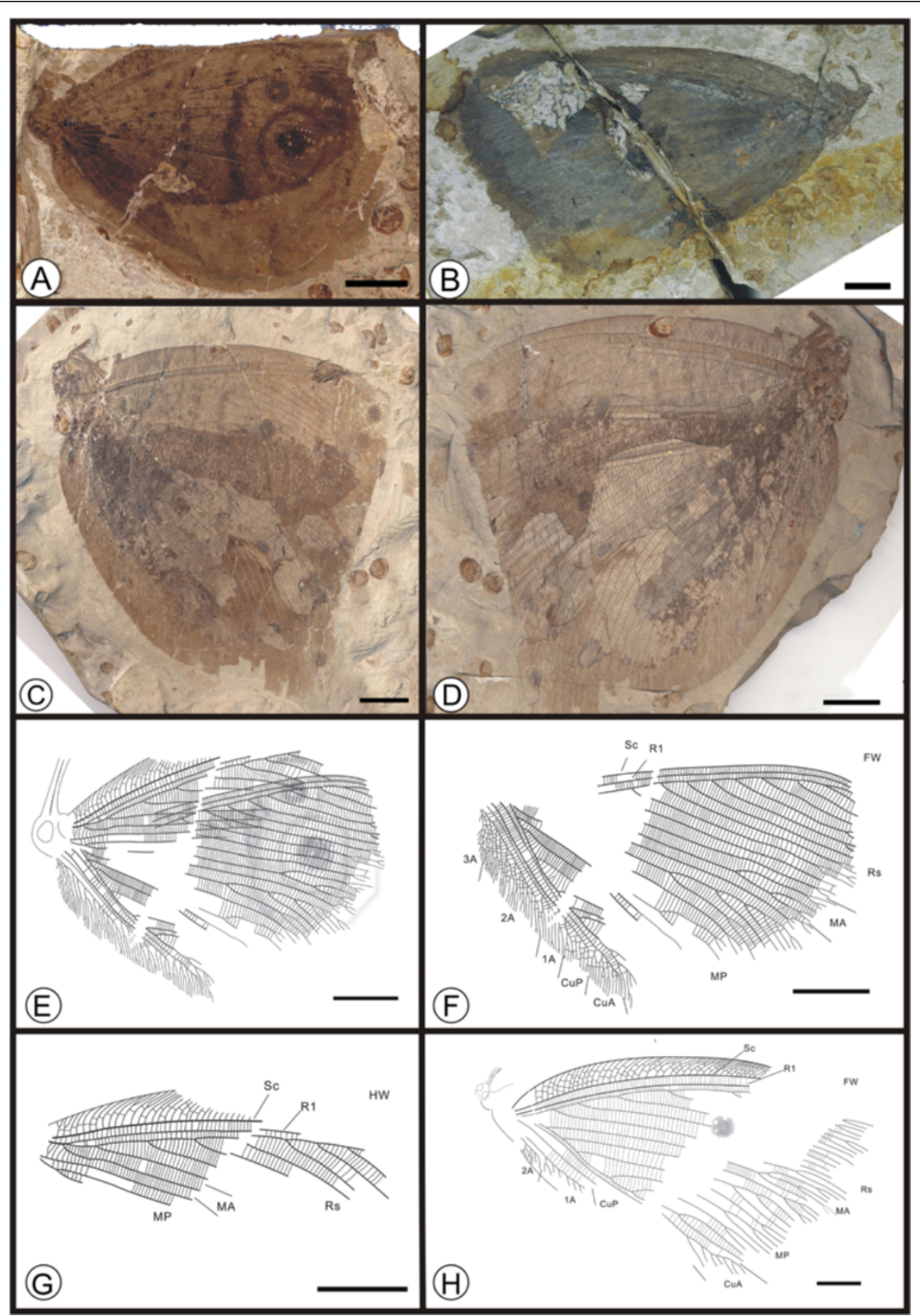

Figure 8 Images and camera lucida drawings of Kalligramma circularia sp. nov. A, Holotype CNU-NEU-NN2010-003; B, Paratype CNU-NEU-NN2010-011; C, D, Paratype CNU-NEU-NN2010-015P/C; E, Outline of holotype; F, Forewing of holotype; G, Hind wing of holotype; H, Outline of paratype CNU-NEU-NN2010-011. Scale bars, $10 \mathrm{~mm}$.

\section{Measurements}

CNU-NEU-NN2010-010P/C (Figure 9A,B): forewing $64 \mathrm{~mm}$ long, $37 \mathrm{~mm}$ wide as preserved.

\section{Description}

Body preserved in lateral view (Figure 9C). Compound eyes large; antennae fragmentary. Proboscis incomplete.
Thorax and abdomen not preserved; portions of forelegs and midlegs preserved. Four wings overlapping; most venation difficult to discern, but apparently crossveins occur throughout the wings.

Forewing approximately obtuse-triangular. Most costal veinlets curved and forked, with dense interlinked veinlets. R1 parallel to $\mathrm{Sc}$ for a considerable distance, then 


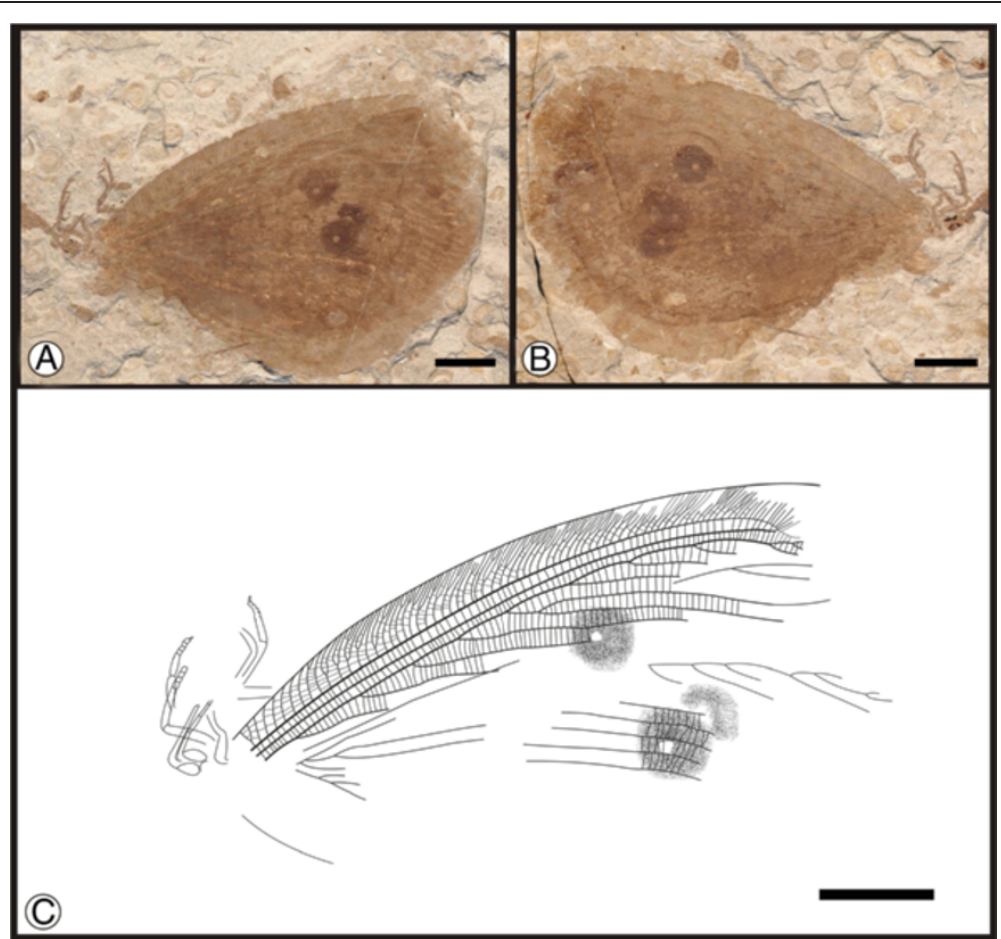

Figure 9 Images and camera lucida drawing of Kalligramma sp. CNU-NEU-NN2010-010P. A, B, Habitus; C, Outline of habitus. Scale bars, $10 \mathrm{~mm}$.

fused apically and curved posteriorly toward wing margin. Rs with ca. 10 primary pectinate branches. Wing eyespot conspicuous on forewing.

\section{Remarks}

The specimen Kalligramma sp. is deemed an indeterminate species, as overlapping wings obscure most of the determinative vein characters.

Subfamily Oregrammatinae subfam. nov.

(urn:lsid:zoobank.org:act:6707AFBB-C7AB-4217-879 F89D57DE947A0)

Type genus. Oregramma Ren, 2003

\section{Included genera}

Type genus, Abrigramma gen. nov., and Ithigramma gen. nov.

\section{Diagnosis}

Apomorphic characters defining the Oregrammatinae are: 1 ), the costal region is strongly constricted toward the wing apex; 2), the second branch of the posterior media vein (MP2) is basally arched; and 3), a broadening of the cubitus region occurs along the midwing interval.

Genus Abrigramma gen. nov.

(urn:lsid:zoobank.org:act:3172C76C-AF70-468D-92 DCA99B4F220BFD)

Type species. Abrigramma calophleba sp. nov.

\section{Diagnosis}

Humeral recurrent veins (Vr) absent. Forewing Rs with at least 9 primary branches, all single. MA pectinately forked, having a false origin from MP. 2A with ca. 13 pectinately forked branches. Hind wing Rs almost originating from $\mathrm{R} 1$ at $1 / 4$ of the distance from its base, branching at ca. apical third of wing length, forming at least 2 primary branches. MP first branch forked nearly at base of wing, third branch terminates at the wing's posterior border, before wing apex. $2 \mathrm{~A}$ with at least 9 pectinate branches; $3 \mathrm{~A}$ short, with 3 pectinate, dichotomous branches.

\section{Etymology}

The generic name is derived from the French abri, a "shelter" or "haven", a modification of the Latin, apricum, for "an open place", referring to the spreading wings of this species; and the Greek, gramma, meaning "lined" or "written", referring to wings provided with a manuscriptlike appearance, also a common suffix of kalligrammatid genera. The gender is feminine.

\section{Remarks}

This new genus and new species, Abrigramma calophleba gen. et sp. nov., is placed in the Kalligrammatidae based on the following characters: 1), the forewing is remarkably large, with a costal area of moderate width; 2), the R1 is 
unbranched; 3), the Rs has numerous pectinate branches; and 4) the MP is extensively branched and provided with several main branches anteriorly and numerous crossveins over the entire wing. The hind wing is noticeably large, with its costal area demonstrably larger than representatives of related families. In addition, the R1 is unbranched, the Rs has few pectinate branches, the MA is forked shallowly along the posterior part of the wing, the MP is pectinately forked, and abundant crossveins occur throughout the wing.

Abrigramma calophleba sp. nov. (Figure 10)

(urn:Isid:zoobank.org:act:3FF1C294-4C34-48FA-B957A08B2C47055E)

\section{Diagnosis}

As for the genus, by monotypy.

\section{Etymology}

The specific epithet, calophleba, is derived from the Greek, kalos, for "beautiful", and phleba, for "vein" of a leaf or insect wing.

\section{Holotype}

A well-preserved specimen (part and counterpart) with most of the forewings preserved; hind wings are present and the axial body is incomplete; specimen CNU-NEUHP2009-001P/C (Figure 10A,B). The sex is unknown.

\section{Type locality and horizon}

Yixian Formation, mid Early Cretaceous, Pingquan County, Chengde City, Hebei Province, China.

\section{Measurements}

Holotype, CNU-NEU-HP2009-001P/C (Figure 10A, B): forewing the preserved portion of length $73 \mathrm{~mm}$ and width $44 \mathrm{~mm}$, hind wing $45 \mathrm{~mm}$ long, $41 \mathrm{~mm}$ wide as preserved.

\section{Description}

A moderately large insect; body partially preserved in dorsal view (Figure 10C). Compound eyes large; antennae filiform. Mouthparts with long, robust proboscis and palpi. Prothorax short, trapeziform; mesothorax pyriform, wider than prothorax. Left foreleg almost complete, with 5 tarsal segments. Setae densely investing body and wings.

Forewing approximately triangular-obtuse, apical angle and outer margin partly missing. Wing eyespot faint. Humeral recurrent veins $(\mathrm{Vr})$ absent; all costal veinlets sinuate, only several forked. R1 parallel to Sc almost to wing margin; Rs traceable almost to base of R1, with at least 9 primary branches, all single. MA pectinately forked, with 3 branches, having a false origin from MP; MP sinuate, with 6 pectinate branches. CuA forked trifurcately near wing margin; $\mathrm{CuP}$ branched near wing margin, with 2 dichotomously pectinate branches. 1A with 3 branches; $2 \mathrm{~A}$ with ca. 13 pectinate branches, occupying most of the posterior wing margin; 3A short and unbranched. Wing spot obvious, consisting of one black, circular splotch.

Hind wing short and broad, almost triangular-acute; posterior area absent. All costal veinlets sinuate. R1 unbranched, parallel to Sc for a long distance; origin of Rs slightly distant from wing base. MA unbranched, dichotomously forked near wing margin; MP pectinately branching, with minimally 5 branches; first branch almost at wing base, third branch terminates at wing's hind margin, before wing apex. $\mathrm{CuA}$ single; $\mathrm{CuP}$ originating from $\mathrm{CuA}$, dichotomously forked. $1 \mathrm{~A}$ unbranched; $2 \mathrm{~A}$ with at least 9 pectinate branches; 3A short, with 3 pectinate, dichotomous branches.

Genus Ithigramma gen. nov.

(urn:lsid:zoobank.org:act:2DF7B863-BB52-46E4-950E56D592AB7F77)

Type species. Ithigramma multinervia sp. nov.

Included species. Type species and Ithigramma sp.

\section{Etymology}

The generic name is derived from the Greek, ithys, meaning "straight", for the rectilinear course of the wing venation of this species; and the Greek, gramma, meaning "lined" or "written", referring to wings provided with a manuscript-like appearance, also a common suffix of kalligrammatid genera. The gender is feminine.

\section{Diagnosis}

Large insects; densely setose or scaled throughout the body and wings. Antennae filiform, short. Mouthparts with elongate palpi, exceeding the head length. Wings with indistinct pterostigma, wing eyespot present.

\section{Remarks}

Ithigramma gen. nov. is different from other genera by the following features: 1 ), the mouthparts are significantly elongate, with palps longer than the head length; and 2), a dense vestiture of setae and scales covers the body and wings. The setae and scales on the wings are frequently so dense that veins are obscured.

Ithigramma multinervia sp. nov. (Figure 11)

(urn:lsid:zoobank.org:act:B98C978B-8A12-4B35-AD3D9C20D692F076)

\section{Diagnosis}

Body robust, densely setose throughout, including the wings, obscuring the venation. Forewings and hind wings each with an eyespot. Forewing costal region narrowed; Sc and R1 fused apically and then curved posteriorly to enter wing margin. Dense crossveins occurring throughout the wings. 


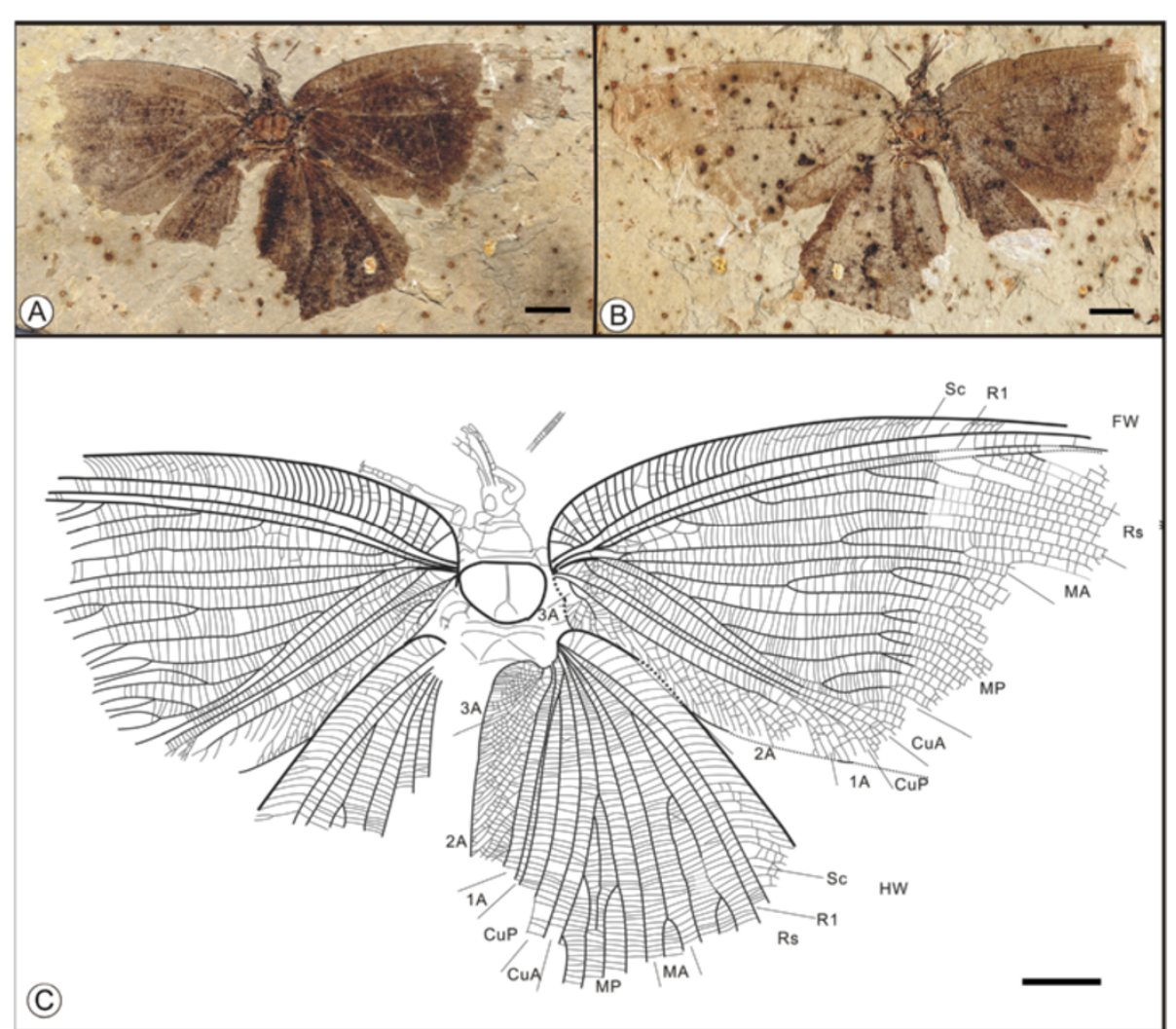

Figure 10 Images and camera lucida drawing of Abrigramma calophleba sp. nov. CNU-NEU- HP2009-001P. A, B, Holotype; C, Outline of holotype. Scale bars, $10 \mathrm{~mm}$.

\section{Etymology}

The specific epithet, multinervia, is derived from the Latin multus, meaning "many", and nervus, meaning "vein".

\section{Holotype}

A poorly preserved specimen (part and counterpart), the structure of both the body and venation is quite indistinct; specimen CNU-NEU-NN2009-034P/C (Figure 11A, B). The sex is unknown.

\section{Type locality and horizon}

Yixian Formation, Early Cretaceous, Liutiaogou Village, Ningcheng County, Inner Mongolia, China.

\section{Measurements}

Holotype, CNU-NEU-NN2009-034P/C (Figure 11A, B): antennae $16 \mathrm{~mm}$ long as preserved; hind wing ca. $71 \mathrm{~mm}$ long, $34 \mathrm{~mm}$ wide.

\section{Description}

Large insects, body partially preserved in lateral view (Figure 11C). Entire body, including wings, densely setose throughout. Body robust; cephalic, thoracic and abdominal structures unclear. Compound eyes poorly defined; antennae filiform. Maxillary palps elongate, longer than head length. Forewings and hind wings overlapping, eyespots visible; venation indistinct, few veins discernible, the margin of each wing unclear. Dense crossveins occurring throughout the wings. Pterostigma unclear; wing eyespot on forewing.

Forewing approximately obtuse-triangular. Costal region narrow; Sc and R1 fused apically, curved posteriorly to enter margin; Rs bearing several pectinate branches.

\section{Ithigramma sp. (Figure 12)}

\section{Material}

A poorly preserved specimen (part and counterpart); body structure and venation indistinct; specimen CNU-NEUNN2010-016P/C (Figure 12A, B). Sex female.

\section{Type locality and horizon}

Yixian Formation, Early Cretaceous, Liutiaogou Village, Ningcheng County, Inner Mongolia, China.

\section{Measurements}

CNU-NEU-NN2010-016P/C (Figure 12A, B): forewing ca. $56 \mathrm{~mm}$ long, $29 \mathrm{~mm}$ wide as preserved. 


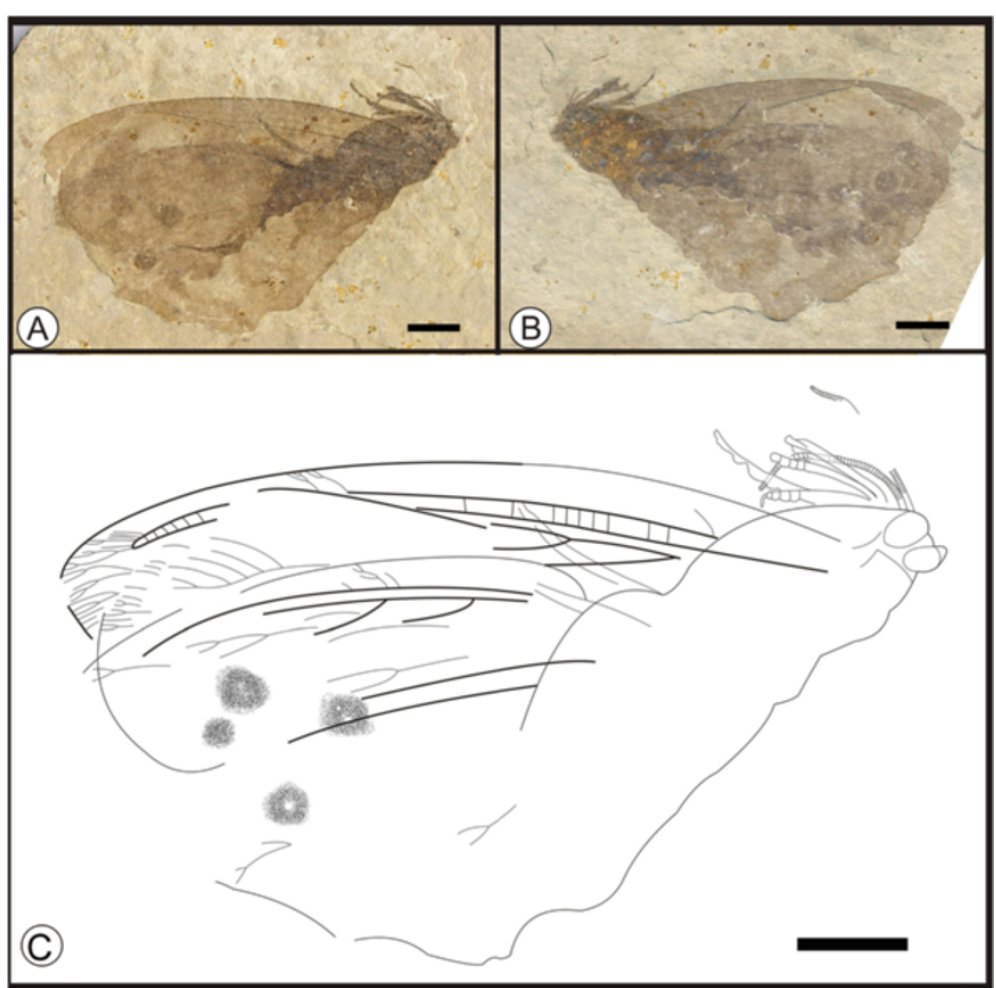

Figure 11 Images and camera lucida drawing of Ithigramma multinervia sp. nov. CNU-NEU-NN2009-034P. A, B, Holotype; C, Outline of holotype. Scale bars, $10 \mathrm{~mm}$.

\section{Description}

Large insects, robust body partially preserved in lateral view (Figure 12C); dense setae and scales throughout the body and overlapping wings. Antennae and compound eyes not identifiable; palpi elongate, longer than head length. Head and thorax structure unclear; abdomen with 5 discernible segments. Legs partly preserved. Venation indistinct, only several main veins recognizable. Dense crossveins occurring throughout the wings.

Forewing approximately obtuse-triangular, the apex smooth. Costal region not broad. Rs with several pectinate branches. Status of other veins not clear. Pterostigma faint; eyespot present on forewing.

\section{Remarks}

The veins of Ithigramma sp. are sparser than those of Ithigramma multinervia sp. nov. Because many characters are not clearly preserved, we cannot attribute this specimen to a species.

Genus Oregramma Ren, 2003

Type species. Oregramma gloriosa Ren, 2003

\section{Included species}

Type species and Oregramma aureolusa sp. nov., Oregramma illecebrosa sp. nov., and Oregramma sp.

Oregramma aureolusa sp. nov. (Figure 13)
(urn:lsid:zoobank.org:act:6046A8CC-4598-45D9-93AFFB764358BBC7)

\section{Diagnosis}

Compound eyes large; palpi elongate. Forewing lacking humeral recurrent veins ( $\mathrm{Vr}$ ). MA pectinately forked; MP sinuate, coursing in an arc, with 8 pectinate branches. $\mathrm{CuA}$ and $\mathrm{CuP}$ branched near wing margin. 1A dichotomously forked near terminus; $2 \mathrm{~A}$ pectinately forked. Forewing with eyespots; pterostigma indistinct. Hind wing pyriform in gross shape; all costal veinlets arched with some crossveins forking near posterior wing margin. R1 simple, with three upturned pectinate branches near terminus. MA dichotomously forked along middle section of wing.

\section{Etymology}

The specific epithet of aureolusa is from the Latin word "aureolus" meaning "made of gold", or figuratively "golden" or "gorgeous".

\section{Holotype}

A well-preserved specimen (part and counterpart) with most of the forewings present, one complete hind wing and an incomplete axial body; specimen CNU-NEUNN2009-032P/C (Figure 13A, B). Sex probably male. 


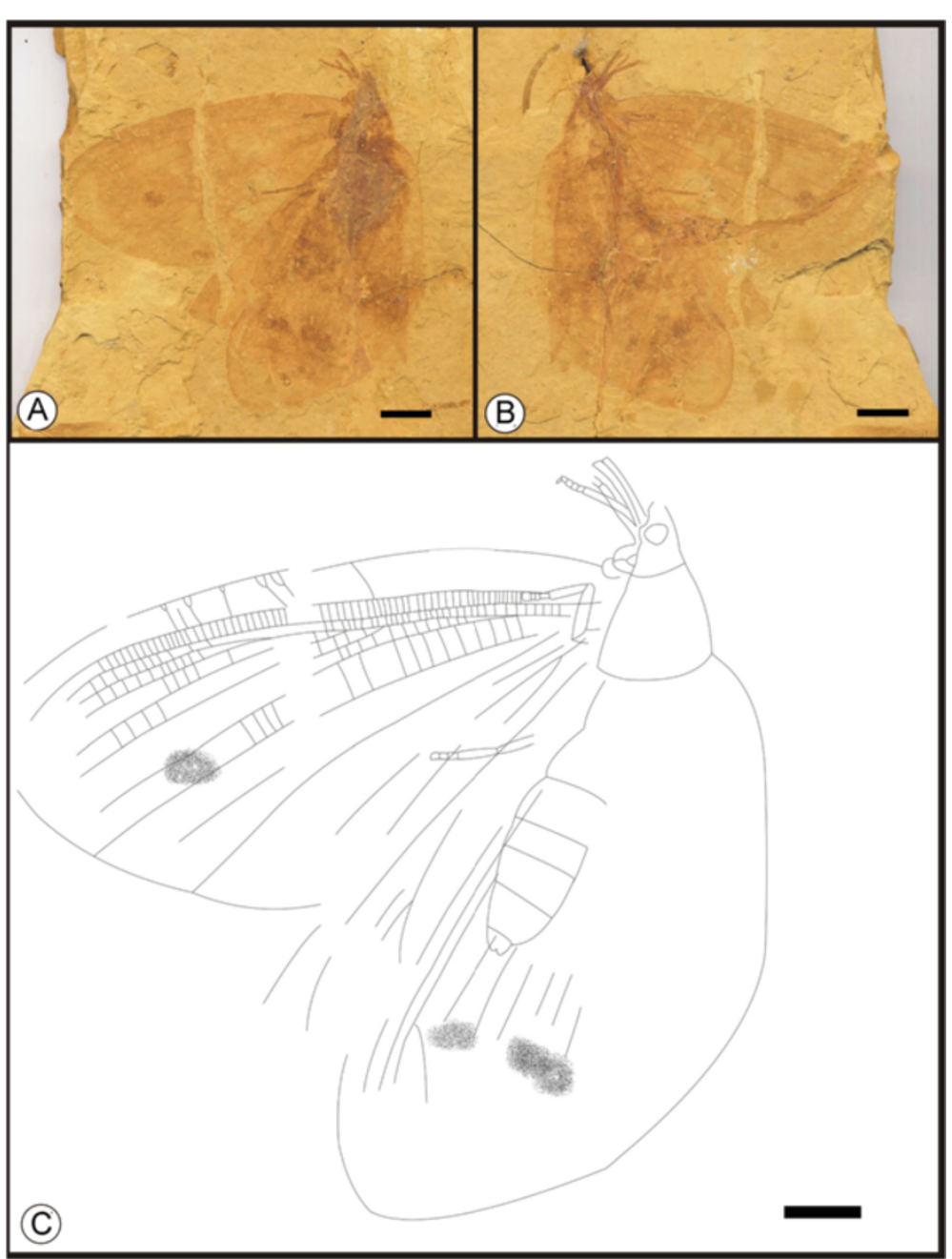

Figure 12 Images and camera lucida drawing of Ithigramma sp. CNU-NEU-NN2010-016P. A, B, Habitus; C, Outline of habitus. Scale bars, $10 \mathrm{~mm}$.

\section{Type locality and horizon}

Yixian Formation, Early Cretaceous, Liutiaogou Village, Ningcheng County, Inner Mongolia, China.

\section{Measurements}

Holotype, CNU-NEU-NN2009-032P/C (Figure 13A,B): antennae ca. $10.5 \mathrm{~mm}$ long; forewing $74.5 \mathrm{~mm}$ long, $41.5 \mathrm{~mm}$ wide as preserved. Preserved hind wing with length $69.0 \mathrm{~mm}$, width $57.0 \mathrm{~mm}$.

\section{Description}

Large insect, body partially preserved in dorsal view (Figure 13C); dense setae and scales covering body and wings. Antennae filiform, with 37 articles. Compound eyes large; proboscis present and palpi elongate. Prothorax short, trapeziform; mesothorax pyriform, wider than prothorax. Fragmentary leg segments preserved. Dense crossveins along all wings.
Forewing approximately obtuse-triangular, apical parts missing. Humeral recurrent veins (Vr) absent. All costal veinlets arched but not forked. R1 parallel to Sc in preserved part; Rs with at least 10 primary branches, all single in the central region. MA pectinately forked, with 3 branches; MP sinuate, forming an arc with 8 pectinate branches. $\mathrm{CuA}$ and $\mathrm{CuP}$ branched near wing margin. $1 \mathrm{~A}$ dichotomously forked near terminus; $2 \mathrm{~A}$ with ca. 13 pectinately forked branches; $3 \mathrm{~A}$ with ca. three simple branches. Eyespot present, distinctive.

Hind wing pyriform in shape. All costal veinlets arched with some forked crossveins entering the apical area. R1 simple, parallel to Sc for a considerable distance, with three upturned pectinate branches terminally; Rs with three branches, the first branching ca. the apical third of wing length. MA dichotomously forked at vein midsection; MP pectinately branching, with 5 branches, first branch nearly at wing base. CuA forked at wing 


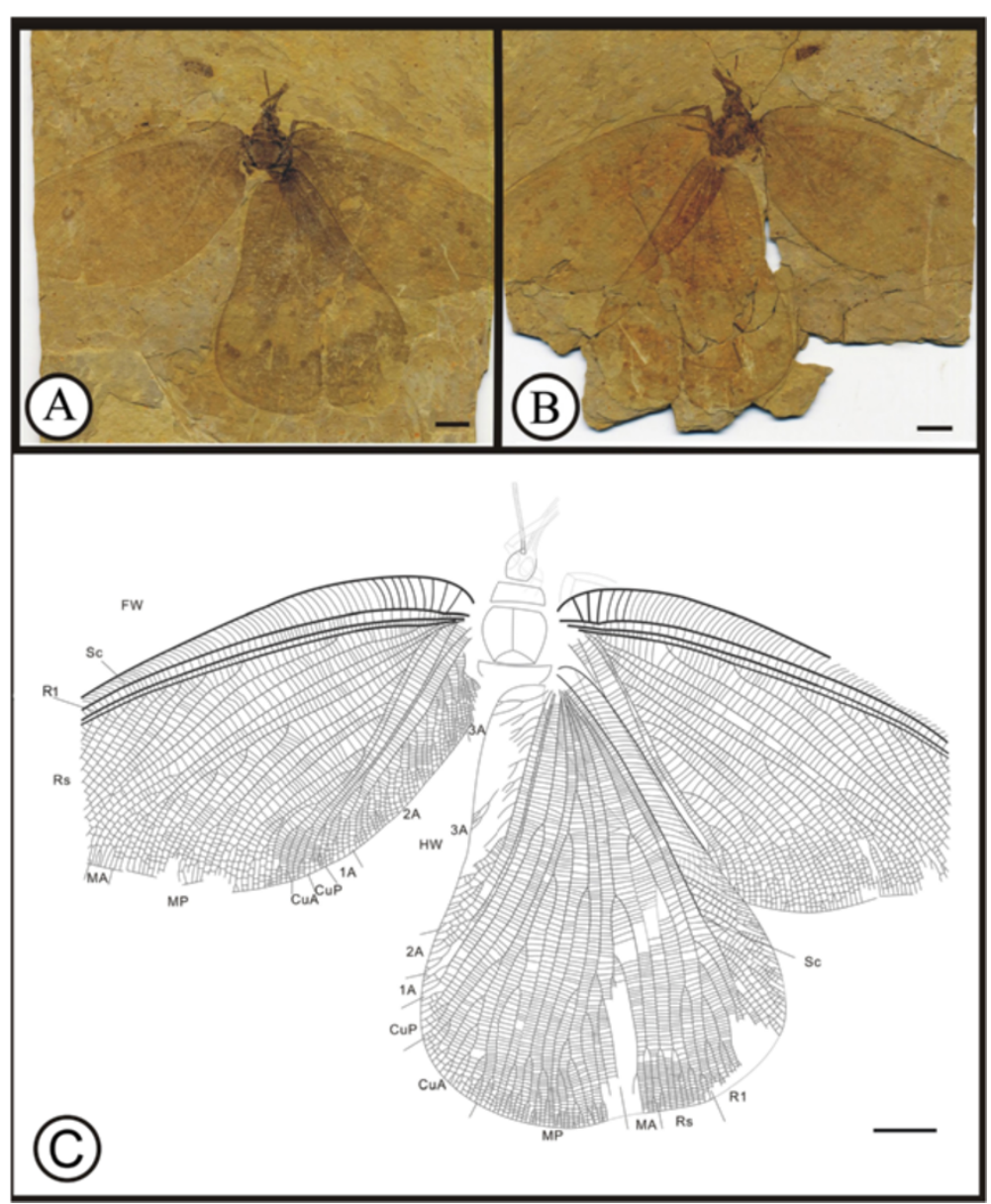

Figure 13 Images and camera lucida drawing of Oregramma aureolosa sp. nov. CNU-NEU- NN2009-032P. A, B, Holotype; C, Outline of holotype. Scale bars, $10 \mathrm{~mm}$.

base, the first branch at wing midsection; the second with three pectinate branches at its base; CuP single. $1 \mathrm{~A}$ simple; $2 \mathrm{~A}$ with ca. 13 pectinate branches; $3 \mathrm{~A}$ faint.

\section{Remarks}

Oregramma aureolusa sp. nov. is attributed to the genus Oregramma based on the above-mentioned characters. Also, it is distinguished from the only known forewing of this genus, Oregramma gloriosa [20], by having the following characters: 1), the MA is pectinately forked, with 3 branches; 2), the MP has 8 pectinate branches; 3 ), the $\mathrm{Cu}$ is divided into $\mathrm{CuA}$ and $\mathrm{CuP}$ near the wing base; 4), the $1 \mathrm{~A}$ is dichotomously forked near its terminus; and 5), the $2 \mathrm{~A}$ subtends ca. 13 pectinately forked branches.

Oregramma illecebrosa sp. nov. (Figure 14)

(urn:lsid:zoobank.org:act:24362312-4249-4EFF-90100ADEF2A33FBF)

\section{Diagnosis}

Siphonate proboscis covered with setae. Ovipositor distinctive; curved and robust. Forewing with prominent eyespots. Most costal veinlets arcuate, only several at the beginning and end are forked. MA with 3 sinuate and pectinate branches at posterior wing margin; MP forked near the wing base, with 6 pectinate branches. $\mathrm{CuA}$ and $\mathrm{CuP}$ simple, with occasional branching. 1A with 3 pectinate branches; $2 \mathrm{~A}$ with ca. 8 pectinate branches; $3 \mathrm{~A}$ with 3 dichotomous branches. Hind wing with Rs of ca. 5 branches, each sequentially forked. MA forked earlier than all branches of Rs, with two dichotomously forked branches; MP pectinately forked. 2A with many pectinate branches.

\section{Etymology}

The specific epithet of illecebrosa is derived from the Latin, "illecebrosus", meaning "attractive" or "charming".

\section{Holotype}

A well-preserved specimen (part and counterpart) with a nearly complete forewing, a fragmentary hind wing covered by forewing and incomplete body, specimen CNU-NEULB2009-031P/C (Figure 14A, B). Female. 


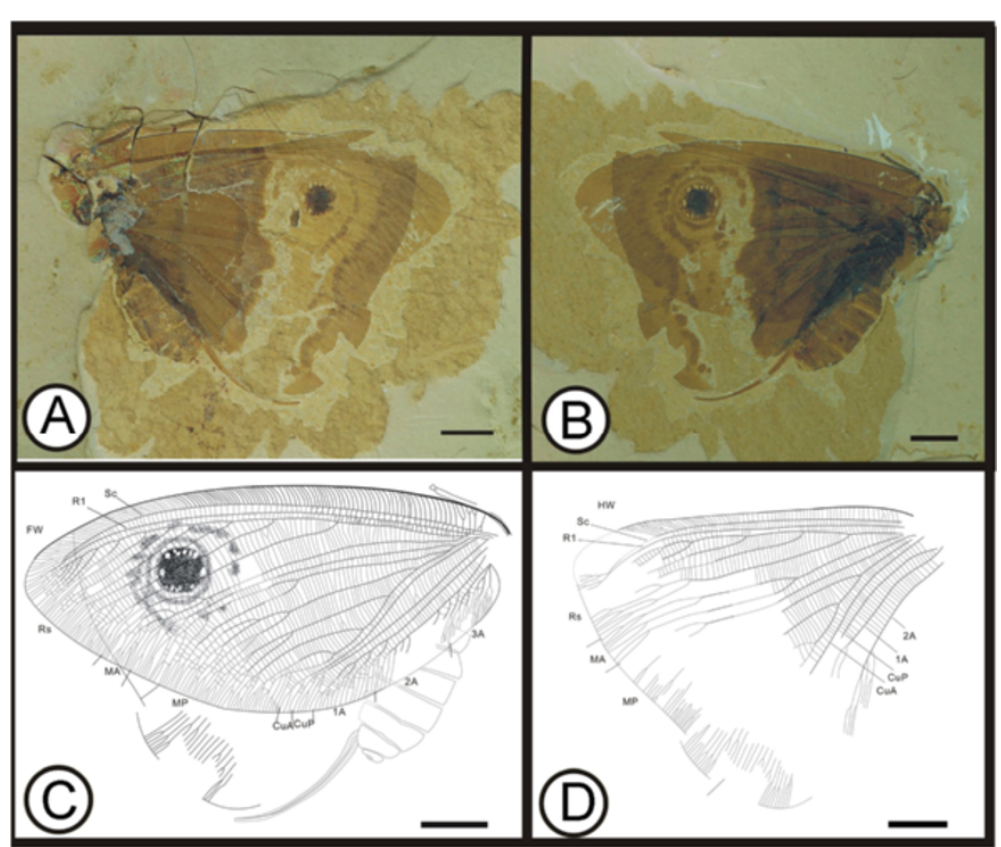

Figure 14 Images and camera lucida drawings of Oregramma illecebrosa sp. nov. CNU-NEU-LB2009-031C. A, B, Holotype; C, Outline of forewing with body; D, Outline of hind wing. Scale bars, $10 \mathrm{~mm}$.

\section{Type locality and horizon}

Yixian Formation, Early Cretaceous, Huangbanjigou, Beipiao City, Liaoning Province, China.

\section{Measurements}

Holotype, CNU-NEU-LB2009-031P/C (Figure 14A, B): ovipositor ca. $25 \mathrm{~mm}$ long; forewing $75 \mathrm{~mm}$ long, ca. $35 \mathrm{~mm}$ wide; hind wing ca. $65 \mathrm{~mm}$ long, $53 \mathrm{~mm}$.

\section{Description}

Body preserved in lateral view (Figure 14C). Head incompletely preserved; antennae faint; incomplete. Maxillary palps mostly missing, some disarticulated articles present; proboscis setaceous. Thorax indistinct; mostly covered by setae. Abdomen well preserved, covered by a setal vestiture; 7 segments discernible and subterminal ovipositor prominent and robust, curved, with two pairs of valves present.

Forewing approximately obtuse-triangular, with obvious eyespot (Figure 14C). Most costal veinlets curved, several beginning and ending crossveins forked. Sc and R1 fused apically and then curved posteriorly to enter margin before the wing apex. Rs with 11 original branches, forked immediately prior to wing apex. MA with 3 sinuate and pectinate branches toward posterior border of wing; MP forked near wing base, with 6 pectinate branches, the first forked later than the second. $\mathrm{CuA}$ and $\mathrm{CuP}$ simple, with limited branching. 1A parallel to $\mathrm{CuP}$ for a significant distance with 3 pectinate branches; $2 \mathrm{~A}$ parallel to $1 \mathrm{~A}$ with ca. 8 pectinate branches; 3A with 3 dichotomous branches. Conspicuous wing eyespot on the forewing.
Hind wing broad, nearly acute-triangular (Figure 14D). Wing margin not evident, most of the hind wing covered by forewing. Most costal veinlets arrayed vertically, some near the apical region curved and forked. Anal veins overlapping body; margins unclear. Sc and R1 fused apically, then curved posteriorly to enter margin before wing apex; Rs with ca. 5 branches, each sequentially forked. MA forked earlier than all branches of Rs, with two dichotomously forked branches; MP with more than 4 pectinately forked branches. CuA parallel to $\mathrm{CuP}$ in the preserved part. $1 \mathrm{~A}$ indistinct; $2 \mathrm{~A}$ partly preserved, with many pectinate branches; $3 \mathrm{~A}$ absent.

\section{Remarks}

Oregramma illecebrosa sp. nov. is probably one of the best preserved of kalligrammatid specimens. This species is assigned to the genus Oregramma based on the above characters. O. illecebrosa is considered a distinct species based on the following characters: 1), O. illecebrosa has a $1 \mathrm{~A}$ pectinately forked whereas in $O$. aureolusa $1 \mathrm{~A}$ is dichotomous near its terminus; and 2), O. illecebrosa has a $2 \mathrm{~A}$ with ca. 8 pectinate branches, whereas in $O$. aureolusa $2 \mathrm{~A}$ has ca. 13 pectinate branches.

Oregramma sp. (Figure 15)

\section{Diagnosis}

Body very robust; head comparatively small. Compound eyes large; siphonate mouthparts present. Forewing without Vr. Rs with ca. 14 primary branches, forked near wing apex. MA bifurcate at vein midsection; MP with more than 4 


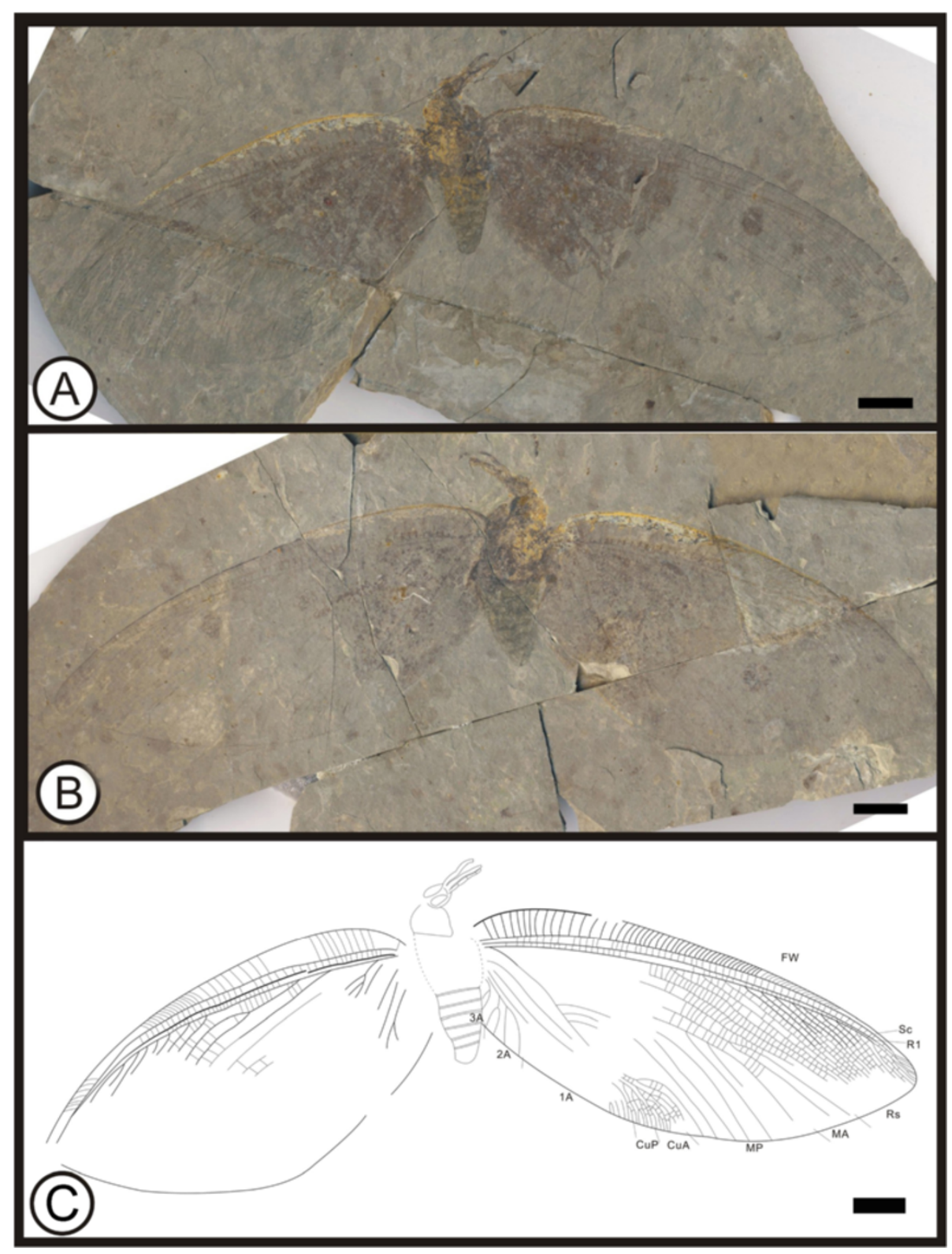

Figure 15 Images and camera lucida drawing of Oregramma sp. CNU-NEU-NN2010-014P. A, B, Habitus; C, Outline of habitus. Scale bars, $10 \mathrm{~mm}$.

pectinate branches. 2A with 2 dichotomous branches; 3A bifurcate. Eyespot indistinct.

\section{Material}

A relatively well-preserved specimen (part and counterpart) with two forewings, and incomplete body; specimen CNUNEU-NN2010-014P/C (Figure 15A, B). Male.

\section{Type locality and horizon}

Yixian Formation, Early Cretaceous, Liutiaogou Village, Ningcheng County, Inner Mongolia, China.

\section{Measurements}

CNU-NEU-NN2010-014P/C (Figure 15A,B): forewing ca. $83 \mathrm{~mm}$ long, $34 \mathrm{~mm}$ wide as preserved.

\section{Description}

Robust body preserved in dorsal view (Figure 15C). Head comparatively small, preserved in oblique-lateral view; compound eyes large; antennae not preserved. Mouthparts relatively long; proboscis truncated. Thorax unclear; abdomen of 6 discernible segments. Forewings almost complete, but venation indistinct. Forewing 
approximately obtuse-triangular. Most costal veinlets curved and not forked, rarely interlinked; Vr absent. Sc and R1 fused apically, then curved posteriorly to enter margin before wing apex. Rs with ca. 14 primary branches, forked immediately before wing apex. MA bifurcate at vein midsection; MP with more than 4 pectinate branches. Posterior wing margin poorly preserved; venation indistinct. $\mathrm{CuA}$ and $\mathrm{CuP}$ simple, with limited branching at their termini. 1A simple at wing base, but absent along the posterior margin; 2A with 2 dichotomous branches; $3 \mathrm{~A}$ bifurcate. Inconspicuous eyespot on forewing.

\section{Remarks}

The specimen is attributed to the genus Oregramma based on the above-mentioned characters. Characters defining this specimen are different from other species of the genus. Because of poorly preserved characters, this specimen is unassigned to a species.

Subfamily Sophogrammatinae subfam. nov.

(urn:Isid:zoobank.org:act:919EE2ED-DDDA-4D31-9011F6317FBA2B4A)

Type genus. Sophogramma Ren \& Guo, 1996

Included genera. Type genus and Protokalligramma Yang, Makarkin \& Ren, 2011.

\section{Diagnosis}

Apomorphic characters defining the Sophogrammatinae are: 1), presence of a humeral recurrent vein (Vr); 2), proximal pectinate branching of the first anal vein (1A); and 3), presence of a long, accessory veinlet at the basal part of the media posterior vein (MP2). Plesiomorphically retained characters are: 1 ), mandibulate mouthparts; 2 ), absence of wing spots and eyespots; and 3) wings that structurally are highly cantilevered.

\section{Remarks}

The new subfamily Sophogrammatinae represents the earliest divergence within the Kalligrammatidae, and possesses plesiomorphies that are distinct from other kalligrammatids, namely the MP branches are parallel, while MP branches in other kalligrammatids form a large triangular region; the presence of mandibulate mouthparts versus a siphonate proboscis occurring in all other groups; and the absence of eyespots, while other groups generally have distinct eyespots on the wings.

Genus: Sophogramma Ren \& Guo, 1996

Type species. Sophogramma papilionacea Ren \& Guo, 1996

Included species. Type species and Sophogramma eucalla Ren and Guo, 1996; Sophogramma lii Yang, Zhao and Ren 2009; Sophogramma plecophlebia Ren and Guo, 1996; and Sophogramma pingquanica sp. nov.

Sophogramma pingquanica sp. nov. (Figure 16)
(urn:lsid:zoobank.org:act:7CB0F600-0EC7-4724-B5F23747CAAB12D6)

\section{Diagnosis}

Forewing Vr prominent; third branch of Rs with early dichotomous forking. MA with 3 sinuate and pectinate branches. $\mathrm{CuA}$ forked at vein midsection. Hind wing MA forked earlier than all branches of Rs; MP bifurcate at wing base. 2A distinctly dichotomously forked.

\section{Etymology}

The specific epithet of pingquanica is dedicated to the locality of the species in Pingquan County, northeastern China.

\section{Holotype}

A well-preserved part and counterpart with complete forewings and hind wings, but incomplete body; specimen CNU-NEU-HP2010-009P/C (Figure 16A, B). Sex unknown.

\section{Type locality and horizon}

Yixian Formation, Early Cretaceous, Pingquan County, Chengde City, Hebei Province, China.

\section{Measurements}

Holotype, CNU-NEU-HP2010-009P/C (Figure 16A, B): antennae $19 \mathrm{~mm}$ long as preserved; forewing $66 \mathrm{~mm}$ long, $33 \mathrm{~mm}$ as preserved; hind wing ca. $44 \mathrm{~mm}$ long, $28 \mathrm{~mm}$ wide.

\section{Description}

Body preserved in dorsal view (Figure 16C). Head partially preserved in dorsal view; compound eyes obvious; antennae filiform, partly preserved, articles unclear. Mouthparts and legs not preserved. Prothorax and thorax indistinct. Hind wings overlapping onto axial body; abdomen with ca. 11 segments discernible. Forewings and hind wings almost complete, but venation unclear.

Forewing approximately obtuse-triangular (Figure 16D); apical area partly missing. Vr present, most of costal veinlets curved and forked. R1 nearly parallel to Sc as preserved; Rs with 11 primary branches; except for the first one, the other branches deeply forked; the third branch $\left(\mathrm{Rs}_{3}\right)$ dichotomously forked earlier. MA with 3 sinuate and pectinate branches, the deeply forked region expansive; MP forked near wing base; MP1 and MP2 forming a loop or cell (bc) basally. CuA forked at the middle of vein; CuP simple but poorly preserved. $1 \mathrm{~A}$ parallel to $\mathrm{CuP}$ for a long distance, with at least 4 pectinate branches; 2A appearing dichotomously forked; 3A simple. Wing eyespot or spot absent.

Hind wing short and broad, nearly acute-triangular. Wing apex absent; most of costal margin hidden by overlap 


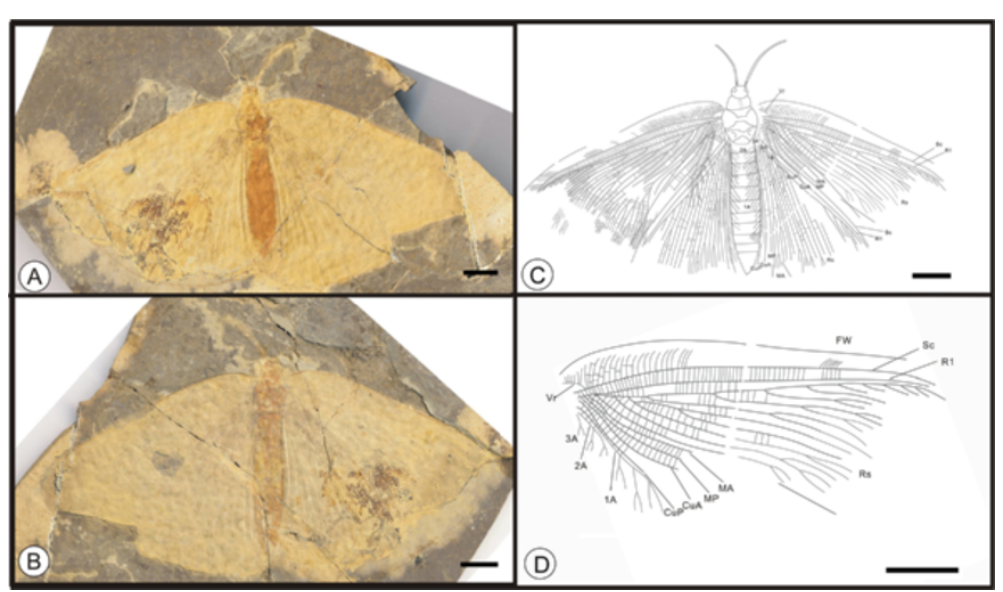

Figure 16 Images and camera lucida drawings of Sophogramma pingquanica sp. nov. CNU-NEU-HP2010-009P. A, B, Holotype; C, Outline of Holotype; D, Outline of forewing. Scale bars, $10 \mathrm{~mm}$.

of forewing anal region; C, Sc and crossveins between them barely discernible. Sc and R1 curved posteriorly, R1 simple; Rs with more than 10 branches, each sequentially forked. MA forked earlier than all branches of Rs, with two deeply forked branches; MP bifurcated at wing base. $\mathrm{CuA}$ simple; $\mathrm{CuP}$ ca. parallel to $\mathrm{CuA}$ at posterior part of wing, displaying more than 4 pectinate branches. Anal veins overlapping onto body, margins unclear; $1 \mathrm{~A}$ with at least 12 pectinate branches; $2 \mathrm{~A}$ distinctly forked, basal branch missing; 3A not present.

\section{Remarks}

Sophogramma pingquanica sp. nov. is attributed to the genus Sophogramma based on the above-mentioned characters. S. pingquanica sp. nov. is the second specimen of this genus preserved with four largely separated wings and an intact body, the first being S. lii [23]. Sophogramma pingquanica sp. nov. is distinguished from other species principally by forewing characters: 1 ), the third branch $\left(\mathrm{Rs}_{3}\right)$ is dichotomously forked earlier than other congeneric species; and 2), the $\mathrm{CuA}$ is forked at the middle of the vein. In addition, the following hind wing features are distinctive: 3 ), the Rs has more than ten primary branches; 4 ), the $\mathrm{CuP}$ has more than four pectinate branches; and 5), the 1A probably has at least twelve pectinate branches.

\section{Key to the genera of Kalligrammatidae}

The classification of the Kalligrammatidae is principally based on the forewing characters. We omit five genera in the following key: Angarogramma [28], and Palparites [4], characterized by poor preservation and the lack of sufficient diagnostic details, as well as Kalligrammina [16], Limnogramma [20], and Sinokalligramma [25], with only hind wings preserved.
1. A. Wing setae sufficiently dense that veins are obscured (Figure 11, 12).

Ithigramma gen. nov.

B. Wing setae relatively sparse, veins quite evident.

$$
2
$$

2. A. Forewing of simple costal veinlets simple with few distal forks. 3

B. Forewing of complex costal veinlets, with many distal forks. 4

3. A. MP1 and MP2 forming a loop or cell (bc) (Figures one-three in [21]) basally........ Sophogramma

B. Absence of the loop or cell (bc) between MP1 and MP2 5

4. A. Presence of ORB between Rs and MA (Figure two in [22]). 6

B. Absence of ORB between Rs and

MA................................................................ 7

5. A. Many rows of basal cells between $\mathrm{CuA} \& \mathrm{CuP}$ and $1 \mathrm{~A} \& 2 \mathrm{~A}$ (Figure 10). Abrigramma gen. nov.

B. Only one row of basal cells between $\mathrm{CuA} \& \mathrm{CuP}$ and $1 \mathrm{~A} \& 2 \mathrm{~A}$. 8

6. A. Two ORBs present near wing base between Rs and MA

(Figure 1)....

Affinigramma gen. nov.

B. Many ORBs present along the main stem of Rs.. 9

7. A. First branch of Rs distal from wing base (Figure three in [11])... Meioneurites

B. First branch of Rs proximal to wing base.

8. A. MP sinuate (Figure 13).

Oregramma

B. MP rectilinear (Figure twenty-six in [15]) Lithogramma 
9. A. More than twenty ORBs; forewing with distinct spots

(Figures four-five in [24])

\section{Apochrysogramma}

B. Ten or less ORBs; forewing without distinct spots. Kallihemerobius

10. A. MP forming a large triangular region.

B. MP stem simple, dichotomously forked (Figures one-two in [24])......... Protokalligramma

11. A. Presence of humeral recurrent vein (Figure 5). 13

B. Absence of humeral recurrent veins. 12

12. A. $\mathrm{CuA}$ and $\mathrm{CuP}$ forked proximally (Figure twentyseven [15]).. Kalligrammula

B. $\mathrm{CuA}$ and $\mathrm{CuP}$ always forked distally

13. A. MP pectinately forked (Figure 5)............ Stelligramma gen. nov.

B. MP dichotomously forked (Figure two in [27]) Huiyingogramma

\section{Discussion}

\section{Results of the phylogenetic analysis}

An analyses using NONA with four successive outgroups resulted in nine most parsimonious trees (MPTs), each consisting of 78 steps $(\mathrm{CI}=0.65, \mathrm{RI}=0.82)$. Species in the same genus were well grouped in the cladogram except for Ithigramma and Oregramma (Additional file 1: Figure S1A-D). The genus Ithigramma with its character of densely setose forewings distinctly differed from Oregramma. However, Ithigramma was nested within an Oregramma clade in the MPTs. This paraphyly probably was caused by poor preservation of the Ithigramma specimen, which lacked sufficient information for differentiation from Oregramma. In addition, the other genera were well grouped monophyletically in the analysis with a minor exception in the interrelationships of Kalligramma (Figure S1).

The analyses by PAUP resulted in $40 \mathrm{MPTs}$, also of 78 steps $(\mathrm{CI}=0.65, \mathrm{RI}=0.82)$, which were similar to the NONA analyses. In both trees of strict consensus and 50\% major consensus, Ithigramma and Oregramma became a paraphyly, with slightly different results vs. the NONA analyses (Additional file 2: Figure S2).

The Bayesian analyses did not adequately resolve the interrelationships of the Kalligrammatidae (Additional file 3: Figure S3), similar to the parsimony analyses. In the Bayesian analyses, the Kalligrammatidae was divided into three paraphyletic groups; however, the clade Kalligramma was not recovered as a monophyly (Additional file 3: Figure S3), same as the results of parsimony analyses. The other apparent discrepancy between Bayesian and parsimony analyses (Additional file 4: Figure S4) involved the placement of Sophogramma, grouped with Kalligrammula, Stelligramma, Lithogramma, Affinigramma, Huiyingogramma and Kallihemerobius, instead of the earliest divergence of the Kalligrammatidae. However, there are some clades in which Bayesian and parsimony analyses agree, confirming three monophyletic groups: Sophogramma, Meioneurites, and an Abrigramma + Ithigramma + Oregramma clade.

\section{Phylogeny of Kalligrammatidae}

Because of incomplete information from a few poorly preserved specimens, not all clades received firm support in the phylogenetic analyses. Based on the phylogenetic results (Additional file 4: Figure S4A, B), we propose a rationalized phylogenetic tree of the Kalligrammatidae that includes all genera, but excludes Palparites (Figure 17). In the phylogenetic analysis, the monophyly of the Kalligrammatidae is firmly recovered, which shares the synapomorphic characters of a complex MA bifurcation and a broad triangular forewing and hind wing. The Kalligrammatidae is divided into five primary clades, allocated to the subfamilies Sophogrammatinae subfam. nov., Meioneurinae subfam. nov., Oregrammatinae subfam. nov., Kalligrammatinae [4] and Kallihemerobiinae [29].

The assemblage of the Sophogrammatinae subfam. nov. was expected, which contains two well-defined genera, Sophogramma [21] and Protokalligramma [24]. However, the phylogenetic position of the subfamily remains in question because of the difference between the parsimony and Bayesian analysis. We note that the clade consisting of the Sophogrammatinae and Kallihemerobiinae received low posterior probability in the Bayesian results (Additional file 4: Figure S4B). The grouping of the Sophogrammatinae and Kallihemerobiinae is likely an artificial construct from incomplete data. Based on the parsimony results, the Sophogrammatinae represents the earliest divergence of the Kalligrammatidae, and is the sister-group to all other kalligrammatids. This subfamily can be differentiated from other subfamilies by the trajectory of the MP, in which both branches are parallel and bent posteriorly and distally, versus the alternate condition in which the $\mathrm{MP}_{1}$ diverges from the $\mathrm{MP}_{2}$ close to the wing base, and forms a large triangular region, present in the other four subfamilies (Figure 17/node 1). However, the absence of eyespots within the Sophogrammatinae [Sophogramma [21,23] and Protokalligramma [24]] distinctly implies a plesiomorphy for Kalligrammatidae (Figure 17/node 1); hence, the occurrence of eyespots in other kalligrammatids should be a derived feature. Nevertheless, the absence of eyespots among Kalligrammula, Meioneurites spectabilis and Angarogramma is likely the result of poor preservation or possibly plesiomorphous retention. The humeral recurrent vein is slightly variable 


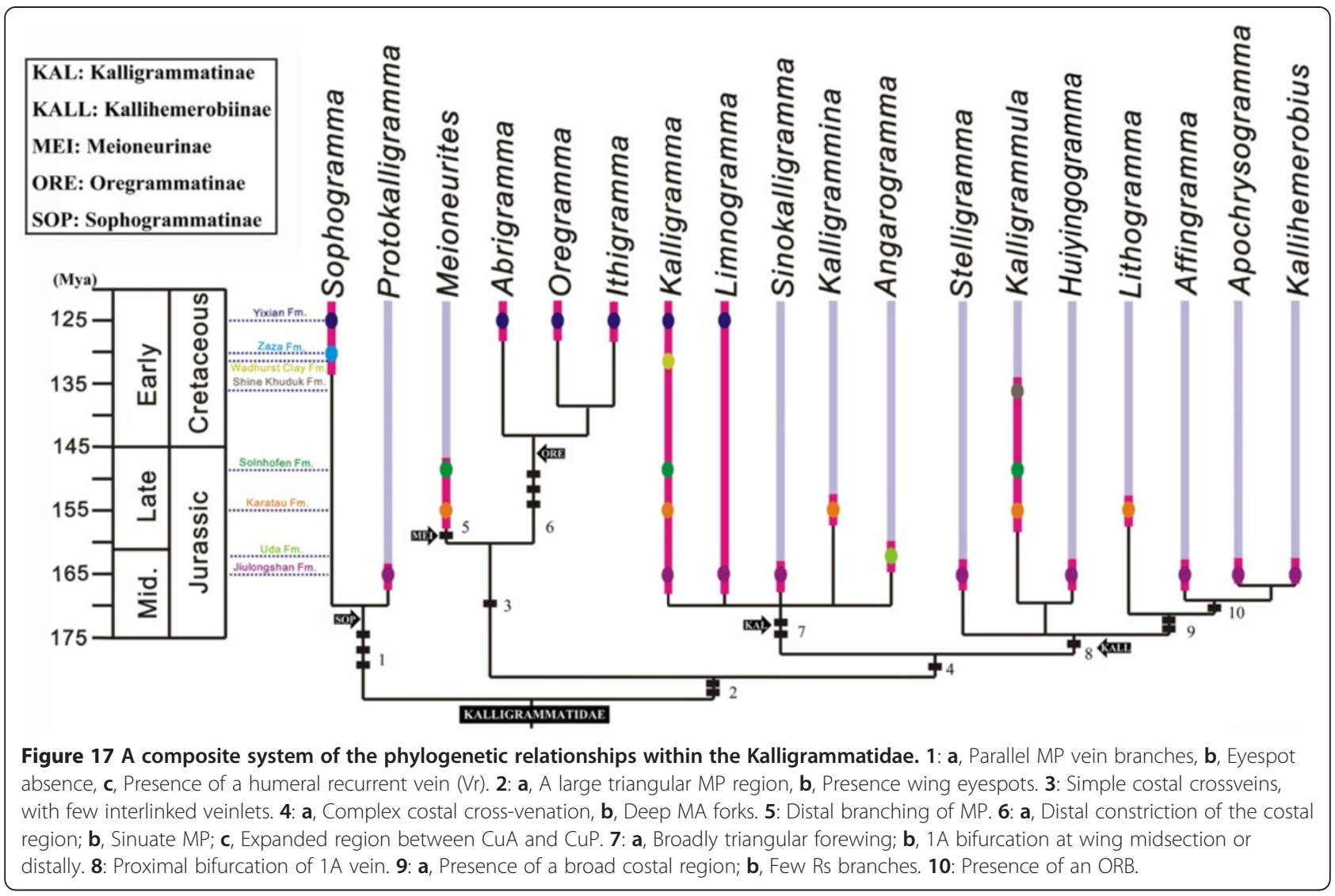

within most Kalligrammatidae, whereas it is well represented in the Sophogrammatinae and can be regarded as a synapomorphy of the subfamily (Figure 17/node 1).

The other four subfamilies share the three synapomorphic characters (Figure 17/node 2) of eyespot presence, and a distinctively triangular MP region. This larger clade is subdivided into two clades, the Meioneurinae subfam. nov. + Oregrammatinae subfam. nov., and the Kalligrammatinae [4] + Kallihemerobiinae [29] (Figure 17/node 3, 4). The sister-group relationships of the Meioneurinae and Oregrammatinae are stable in the phylogenetic analysis, and weakly supported by the two homoplasious characters of less interlinked veinlets along the costal region and simple distal $\mathrm{Cu} 1$ forks. The subfamily Meioneurinae consists of only one genus, Meioneurites [4], from the Late Jurassic, and has the character of distal branching of MP (Figure 17/node 5). The subfamily Oregrammatinae includes three highly homogenous genera: Oregramma [20], Abrigramma gen. nov., and Ithigramma gen. nov., that share the three synapomorphic characters of a distally constricted costal region, a sinuate MP close to the wing base and a medially broadened $\mathrm{Cu}$ region (Figure 17/node 6).

Although the Kalligrammatinae and Kallihemerobiinae are not grouped as a clade in the Bayesian analyses, we prefer the sister relationship of the Kalligrammatinae and Kallihemerobiinae that was firmly supported by the character of a deep MA bifurcation in the parsimony results (Figure 17/node 4). In the analyses, the iconic genus Kalligramma was not fully recovered from the Bayesian results (Additional file 3: Figures S3, Figure 4). However, Kalligramma is well established by the single synapomorphic character of a distal complex $\mathrm{CuA}$ bifurcation in the parsimony analysis (Additional file 1: Figures S1, Figure 2). We consider the controversial placement of this genus might be caused by poor preservation of the specimens. Herein, we tentatively assign four other kalligrammatine-like genera - Angarogramma [28], Limnogramma [20], Kalligrammina [16] and Sinokalligramma [25] - to the subfamily Kalligrammatinae based on the presumed characters of a broadly triangular forewing and hind wing, and a $1 \mathrm{~A}$ vein forked medially or distally (Figure 17/node 7). The interrelationships of Kalligrammatinae currently are not fully resolved because of an inordinate amount of missing data.

In the phylogenetic results the monophyly of Kallihemerobiinae is partially recovered, principally based on sharing the single plausible character of a proximal bifurcation of the $1 \mathrm{~A}$ vein, retrieved from the parsimony analysis (Figure 17/node 8). Based on the results of our analysis, we expand the definition of the Kallihemerobiinae. As for the former definition of the subfamily based on the presence of the ORB, only three genera, Affinigramma, 
Apochrysogramma and Kallihemerobius, can be attributed to the Kallihemerobiinae (Figure 17/node 10). The affiliation of the four heterogeneous genera of Stelligramma, Kalligrammula, Huiyingogramma and Lithogramma to the subfamily is not consistent with our current knowledge, which is probably the result of poor preservation for specimens of these genera. The genus Lithogramma seems to be related to the traditional Kallihemerobiinae, sharing a similar expanded costal region and fewer Rs branches (Figure 17/node 9). The genera Huiyingogramma, Kalligrammula and Stelligramma are attributed to Kallihemerobiinae temporarily, pending future additional evidence to determine their subfamilial status.

Although the interrelationships among the subfamilies are not fully resolved, our analyses are an initial probe into the internal phylogeny of Kalligrammatidae. Future fossil discoveries and additional structural evidence, as they become available, as well as new analyses, will further a more secure placement of the less character-rich taxa.

\section{Diversity of the Kalligrammatidae}

The Kalligrammatidae were a dominant lineage among Neuroptera during the Mesozoic Era, as measured by speciosity. From the histograms of species and generic richness (Figure 18A), kalligrammatids were well established and exhibited, as a group, a relatively flat level of diversity from the late Middle Jurassic at $165 \mathrm{Ma}$ to the mid Early Cretaceous at $125 \mathrm{Ma}$., and are recorded from important Eurasian deposits. However, the internal composition of taxa does vary (Figure 18B). The diversity of the subfamily Kallihemerobiinae, for example, gradually decreases from the later Middle Jurassic to the earlier Early Cretaceous. A similar pattern also was present for the subfamily Kalligrammatinae, abundant during the Middle Jurassic and Late Jurassic, but slackening considerably during the Early Cretaceous. The two sister subfamilies of Meioneurinae and Oregrammatinae occur solely during the Late Jurassic and Early Cretaceous, respectively, revealing the independent origin of new phylogenetic lineages long after earlier kalligrammatid lineages were established during the earlier Jurassic. The subfamily Sophogrammatinae was recorded from two separate periods: the Middle Jurassic, where it probably represents the most basal kalligrammatid lineage, and the Early Cretaceous, implying a temporally displaced rediversification of the subfamily.

As for most neuropterans, kalligrammatids probably were weak flyers, and the typically large body size undoubtedly made them easy targets for contemporaneous predators. The same condition also occurred in other Mesozoic groups of the Neuroptera, the extinct Aetheogrammatidae [29], Saucrosmylinae [33], Grammolingiidae [34] and Panfiloviidae [35], all of which possessed rather large body size. For survival and reproduction, these large insects required special avoidance strategies. Wang et al. [36] reported that the earliest and only known pinnate leaf mimesis by lacewings was Bellinympha filicifolia [36] and Bellinympha dancei [36], both from the late Middle Jurassic. This association exhibited unique behavioral features, revealing a specialized association between insects and gymnosperms that was lost in more recently derived lineages. As for the Kalligrammatidae, the group presents several morphological and behavioral innovations (Figure 19). The presence of eyespots in the Kalligrammatidae implies that kalligrammatids were probably diurnal insects. Sophogramma lii possesses two symmetrical, undulate light-colored stripes near the outer wing margin [23], which can be interpreted as a disruptive coloration (Figure 19A). In a related phenomenon, Olofsson et al. [37] reported wing-margin eyespots in a lepidopteran that reduced attacks on vital body parts by birds. The marginal markings on Sophogramma lii likely had a similar defensive function, misleading predators to attack the wing margin instead of vital, axially located body parts.

During the 40 million years from the late Middle Jurassic (165 Ma) to mid Early Cretaceous (125 Ma), the Kalligrammatidae may have provided an important role in their relationships with plants and avoidance of predators. Kalligrammatids bore either mandibulate or more commonly siphonate mouthparts, often deployed wing markings, including stripes, spots and eyespots and displayed varied wing shapes, indicating that the Kalligrammatidae underwent an evolutionary diversification during the mid-Mesozoic. The disappearance of Kalligrammatidae and absence of their diverse features in modern neuropterans is enigmatic, although there may be modern analogs $[2,38]$. The eventual extinction of these giant insects may have been precipitated by the emergence of angiosperms and associated environmental turnover that began during the mid-Early Cretaceous.

\section{Conclusions}

New fossils from China provide insight into the evolution of the Kalligrammatidae, and suggest that Eastern Eurasia may have been the center of origin for the family during the mid-Mesozoic. Based on phylogenetic analyses and detailed morphological characters, we describe several new genera and species, and propose a new classification encompassing the Kalligrammatidae that is partitioned into five principal clades that are accorded subfamilial rank. They are Sophogrammatinae subfam. nov., Meioneurinae subfam. nov., Oregrammatinae subfam. nov., Kalligrammatinae [4] and Kallihemerobiinae [29]. Kalligrammatids are perhaps the most successful Mesozoic neuropteran lineage, exhibiting an extraordinary breadth of form, taxonomic diversity and ecological 


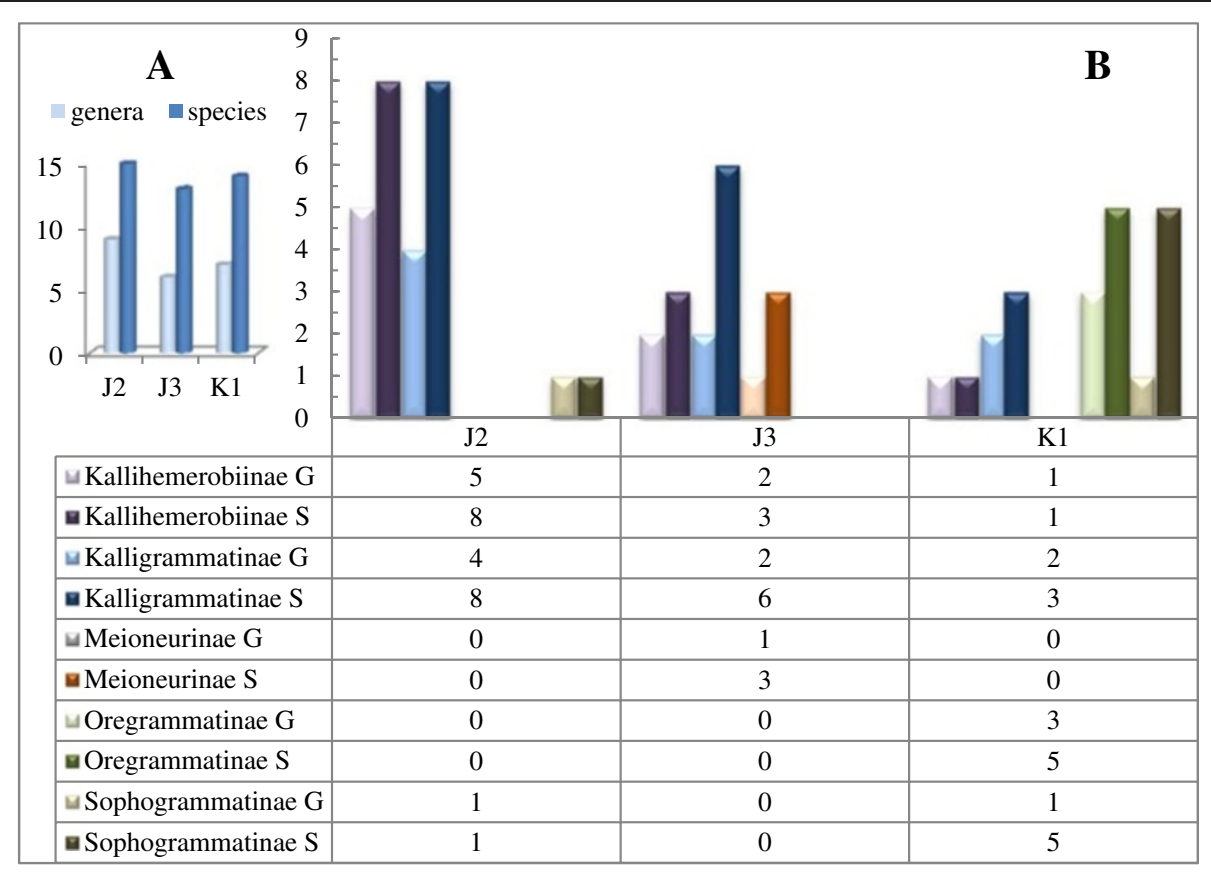

Figure 18 Histograms of kalligrammatid species and generic diversity during their $\mathbf{4 0}$ million-year existence during the mid Mesozoic. A, Histogram showing the genus and species richness of the Kalligrammatidae. B, Histogram showing the genus and species richness at the subfamilial level within the Kalligrammatidae.

dominance that included a variety of plant-insect associations and deterrence from predators. These features indicate that the evolutionary biology of mid Mesozoic kalligrammatid lacewings was more complex than previously realized.

\section{Methods}

The specimens were examined under a Leica MZ12.5 dissecting microscope (Leica, Wetzlar, Germany). Line drawings were prepared with CorelDraw 12 graphic software with the assistance of Photoshop CS2 (Adobe

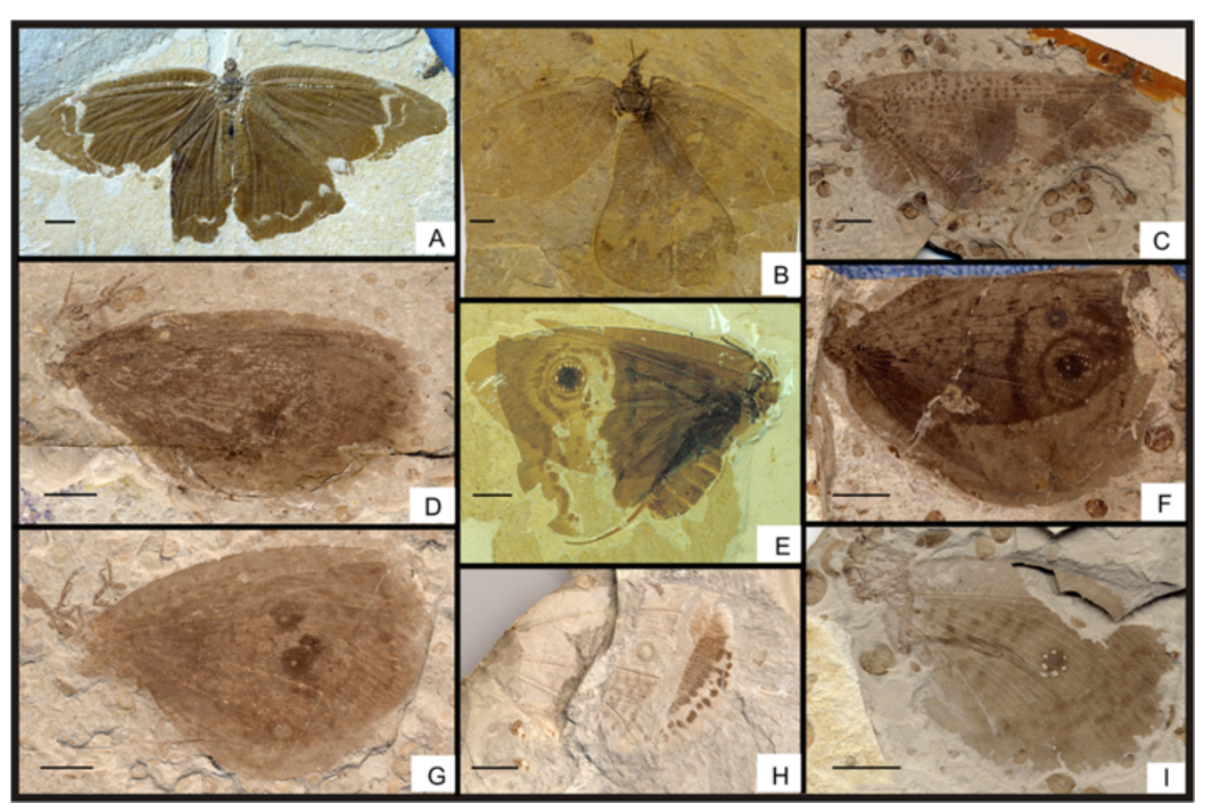

Figure 19 Structural diversity among Kalligrammatidae. A, Sophogramma lii Yang, Zhao and Ren, 2009. B, Oregramma aureolosa sp. nov. C, Stelligramma allochroma sp. nov. D. Affinigramma myrioneura sp. nov. E, Oregramma illecebrosa sp. nov. F, Kalligramma circularia sp. nov. G, Affinigramma myrioneura sp. nov. H, Apochrysogramma rotundum Yang, Makarkin and Ren, 2011. I, Kalligramma brachyrhyncha sp. nov. 
Systems, Mountain View, California). The photographs were taken by Epson Perfection 1650 and Nikon D100 digital cameras. Magnified images of key specimen areas were taken with a Nikon SMZ1000 stereo microscope. All type materials described in this report are deposited in the Key Lab of Insect Evolution and Environmental Changes, College of Life Sciences, Capital Normal University, in Beijing, China (CNUB; Dong Ren, Curator). The LSID for this publication on ZooBank is: urn: lsid:zoobank.org:pub:1CDD4A8D-E8FB-4FE8-AF1E3051B9273EC1.

We conducted a phylogenetic analysis using morphological data from 27 comparatively character-rich specimens of kalligrammatids and related outgroups. Eleven specimens are newly described and sixteen are from the literature. The phylogenetic analysis was overwhelmingly (28 of 30) based on forewing characters (Additional file 5), as kalligrammatid taxa are fundamentally erected on forewing vein structure. Ten genera of the Kalligrammatidae, including 23 species, were sampled in the analysis. Because some previously described species consisted only of hind wings, or information was minimal from the original descriptions, some taxa were too limited to be adequately scored. Seventeen other species were omitted in the analysis (Additional file 6: Table S1). With respect to the peculiar venation of the Kalligrammatidae, four representative genera in other neuropteran families were selected as outgroups, previously reported as closely related to Kalligrammatidae: Saucrosmylus (Osmylidae) [33], Panfilovia (Panfiloviidae) [16], Aetheogramma (Aetheogrammatidae) [29] and Grammolingia (Grammolingiidae) [34].

The matrix consists of 28 taxa and 30 morphological characters and their character states, displayed in Additional file 7: Table S2. The taxa-character matrix was edited using a NEXUS Data Editor (version 0.5.0). All characters were treated as unordered states, and weighted equally. The tree search was conducted by two different inference strategies, parsimony analyses and Bayesian analyses, in order to find preferred cladograms. In parsimony analyses, two phylogeny-seeking programs were employed: WinClada/NONA, and PAUP version 4.0b10. The data matrix was subjected to NONA [39] analyses, employing a heuristic parsimony analysis, with options set to hold 10000 trees, perform 1000 replications with one starting tree replication, and use of a multiple TBR + TBR search strategy. Because NONA can use only one defined outgroup for each analysis, we conducted the cladistic analyses by using each of the four outgroups in successive searches. In PAUP, parsimony analyses were conducted using the branch-and-bound algorithm [40]. Bremer decay indices were obtained using command files composited by TreeRot, version 3 [41], in conjunction with the heuristic search algorithm in PAUP version 4.0b10.
Bayesian inference analyses were conducted with MrBayes version 3.1.2 [42,43]. The maximum likelihood setting referred to the discrete morphological model developed by Lewis [44]. The morphological data were modeled under the assumption that only the variable characters among taxa were included, and gamma-shaped rate variation was enforced. Prior probabilities were kept at their default settings for standard (morphological) analyses. Each analysis was run for $10^{6}$ generations. Samples were taken every $10^{2}$ generations, resulting in a total of $10^{4}$ samples for each of the parallel analyses. The first $2.5 \times 10^{3}$ samples were discarded, representing the "burn-in" period. As with NONA, MrBayes 3.1.2 also was limited to using one defined outgroup for each analysis, which was implemented using each outgroup successively.

\section{Additional files}

Additional file 1: Figure S1. 50\% majority-rule consensus tree of 9 MPTs from NONA. A, Saucrosmylus assigned as outgroup; B, Panfilovia assigned as outgroup; C, Grammolingia assigned as outgroup; D, Aetheogramma assigned as outgroup. Numbers represent percentage support values.

Additional file 2: Figure S2. Phylogenetic results from PAUP. A, Strict consensus tree, The Bremer decay index is indicated at each branch; B, $50 \%$ majority-rule consensus tree of 40 MPTs by PAUP.

Additional file 3: Figure S3. Phylogenetic trees from Bayesian analyses. A, Saucrosmylus assigned as outgroup; B, Panfilovia assigned as outgroup; C, Aetheogramma assigned as outgroup; D, Grammolingia assigned as outgroup. Values associated with nodes indicate posterior probabilities.

Additional file 4: Figure S4. Comparison between parsimony and Bayesian results. $\mathbf{A}$, The best supported tree of the most parsimonious trees. B, The Bayesian tree.

Additional file 5: List of characters and character states for phylogenetic analysis.

Additional file 6: Table S1. Genera and species omitted in the analyses.

Additional file 7: Table S2. Taxon-character-state matrix.

\section{Competing interests}

The authors declare that they have no competing interests.

\section{Authors' contributions}

QY, YJW, CCL, CKS carried out fossil processing, photography, figure preparation, data analysis and interpretation, drafting of manuscript and completion of study. DR conducted fieldwork, specimen collection, data analysis, and manuscript review and revision. All authors read and approved the final manuscript.

\section{Acknowledgments}

We sincerely thank Prof. Michael S. Engel (Kansas University, Kansas, USA), the editor, and two anonymous reviewers for their helpful comments and suggestions. We also express our thanks to Ms. Wenying Wu for the preparation of a previous version of photo for the specimen (CNU-NEU-NN2009-033). This research is supported by the National Basic Research Program of China (973 Program) (grant 2012CB821906), the National Natural Science Foundation of China (grants 31230065, 31272352, 31301905, 41372013 and 41272006), Great Wall Scholar and KEY project of Beijing Municipal Commission of Education (grant KZ201310028033), Program for Changjiang Scholars and Innovative Research Team in University (IRT13081), China Postdoctoral Science Foundation (grant 2012T50113), Ph.D. Programs Foundation of Ministry of Education of China (grant 20131108120005), the Beijing Municipal Natural 
Science Foundation (grant 5132008), and the Doctoral Scientific Research Foundation of Shijiazhuang University of Economics (BQ201326). Finnegan Marsh assisted in the placement and formatting of the figures. This is contribution 258 from the Evolution of Terrestrial Ecosystems Consortium of the National Museum of Natural History, in Washington, D.C.

\section{Author details}

${ }^{1}$ College of Life Sciences, Capital Normal University, Beijing 100048, China. ${ }^{2}$ Department of Paleobiology, National Museum of Natural History, Smithsonian Institution, Washington, DC 20013, USA. ${ }^{3}$ Department of Entomology, University of Maryland, College Park, MD 20742, USA. ${ }^{4}$ Geoscience Museum, Shijiazhuang University of Economics, Shijiazhuang 050031, China.

Received: 3 August 2012 Accepted: 23 April 2014 Published: 9 June 2014

\section{References}

1. Grimaldi D, Engel MS: Evolution of the insects. New York: Cambridge University Press; 2005:335-351.

2. Aspöck U, Aspöck H: Phylogenetic relevance of the genital sclerites of Neuropterida (Insecta: Holometabola). Syst Entomol 2008, 33:97-127.

3. Carpenter EM: Superclass Hexapoda. In Treatise on Invertebrate Paleontology Arthropoda 4. Edited by Moore RC, Kaesler RL. Kansas: Geological Society of America, and University of Kansas Press; 1992:338-356.

4. Handlirsch A: Die fossilen Insekten und die Phylogenie der rezenten Formen. Ein Handbuch für Paläontologen und Zoologen. Leipzig: W. Engelmann; 1906-1908:1-1430.

5. Handlirsch A: Eine neue Kalligrammide (Neuroptera) aus dem Solnhofen Plattenkalke. Senkenbergiana, Frankfurt am Main 1919, 1:61-63.

6. Lambkin KJ: Palparites deichmuelleri Handlirsch from the Tithonian Solnhofen Plattenkalk belongs to the Kalligrammatidae (Insecta: Neuroptera). Palaeontol Z 1994, 68:163-166.

7. Whalley PES: Mesozoic Neuroptera and Raphidioptera (Insecta) in Britain. Bull Br Mus Nat Hist 1988, 44:45-63.

8. Jarzembowski E: A new Wealden fossil lacewing. In Tunbridge Wells and Rusthall Commons, a History and Natural History. Edited by Rowlands ML. Tunbridge Wells: Tunbridge Wells Museum and Art Gallery; 2001:48-58.

9. Walther J: Die Fauna der Solnhofener Plattenkalke. Denkschr Med-Naturwiss Ges Jena 1904, 11:133-214.

10. Cockerell TDA: The Jurassic insects of Turkestan. Psyche 1928, 35:126-130

11. Engel MS: A remarkable kalligrammatid lacewing from the upper Jurassic of Kazakhstan (Neuroptera: Kalligrammatidae). Trans Kansas Acad Sci 2005, 108:59-62.

12. Makarkin VN: New psychopsoid Neuroptera from the Lower Cretaceous of Baissa, Transbaikalia. Ann Soc Entomol France (NS) 2010, 46:254-261.

13. Martynova OM: Kalligrammatidae (Neuroptera) from Jurassic shales of Kara-Tau (Kazakh SSR). Dokl Akad Nauk SSSR 1947, 58:2055-2068

14. Martynova OM: Superorder Neuropteroidea. In Fundamentals of Paleontology - Tracheata and Chelicerata. Edited by Davis DR. Moscow: Academy of Science of the USSR; 1962:383-404.

15. Panfilov DV: Kalligrammatids (Neuroptera, Kalligrammatidae) from the Jurassic deposits of Karatau. In Jurassic insects of Karatau. Edited by Rohdendorf BB. Moskva: Otdelenie Obshchej Biologii; 1968:166-174.

16. Panfilov DV: New representatives of lacewings (Neuroptera) from the Jurassic of Karatau. In Fossil insects of the Mesozoic. Edited by Dolin VG, Panfilov DV, Ponomarenko AG, Pritykina LN. Kiev: Naukova Dumka; 1980:82-111.

17. Ponomarenko AG: Neuroptera (Insecta) from the Lower Cretaceous of Transbaikalia. Paleontol J 1992, 26:56-66.

18. Scudder SH: Systematic review of our present knowledge of fossil insects, including myriapods and insects. US Geol Surv Bull 1886, 31:1-128.

19. Makarkin VN, Ren D, Yang Q: Two new species of Kalligrammatidae (Neuroptera) from the Jurassic of China, with comments on venational homologies. Ann Entomol Soc Am 2009, 102:964-969.

20. Ren D: Two new Jurassic genera of kalligrammatids from Beipiao, Liaoning (Neuroptera, Kalligrammatidae). Acta Zootaxon Sin 2003, 28:105-109. in Chinese, English abstract.

21. Ren D, Guo ZG: On the new fossil genera and species of Neuroptera from late Jurassic of Northeast China. Acta Zootaxon Sin 1996, 21:461-480.

22. Ren D, Oswald JD: A new genus of kalligramtid lacewings from the Middle Jurassic of China (Neuroptera). Stutt Beit Nat Ser B 2002, 317:1-8.
23. Yang $Q$, Zhao YY, Ren D: An exceptionally well-preserved fossil Kalligrammatid from the Jehol Biota. Chin Sci Bull 2009, 54:1732-1737.

24. Yang $\mathrm{Q}$, Makarkin VN, Ren D: Two interesting new genera of Kalligrammatidae (Neuroptera) from the Middle Jurassic of Daohugou, China. Zootaxa 2011, 2873:60-68

25. Zhang JF: Kalligrammatid lacewings from the upper Jurassic Daohugou formation in inner Mongolia, China. Acta Geol Sin 2003, 77:141-147.

26. Zhang JF, Zhang HC: Kalligramma jurarchegonium sp. nov. (Neuroptera: Kalligrammatidae) from the Middle Jurassic of northeastern China. Orien Ins 2003, 37:301-308.

27. Liu $Q$, Zheng DR, Zhang $Q$, Wang B, Fang Y, Zhang HC: Two new kalligrammatids (Insecta, Neuroptera) from the Middle Jurassic of Daohugou, Inner Mongolia, China. Alcheringa 2013, 38:65-69.

28. Ponomarenko AG: Neuroptera from the Jurassic in eastern Asia. Paleontol J 1984, 18:59-69.

29. Ren D, Engel MS: Aethogrammatidae, a new family of lacewings from the Mesozoic of China (Neuroptera: Myrmeleontiformia). J Kansas Entomol Soc 2008, 81:161-167.30

30. Oswald JD: Revision and cladistic analysis of the world genera of the family Hemerobiidae (Insecta: Neuroptera). J New York Entomol Soc 1993, 101:143-299.

31. Makarkin VN, Menon F: First record of fossil 'rapismatid-like' Ithonidae (Insecta, Neuroptera) from the Lower Cretaceous Crato Formation of Brazil. Cret Res 2007, 28:743-753.

32. Wedmann S, Makarkin VN: A new genus of Mantispidae (Insecta: Neuroptera) from the Eocene of Germany, with a review of the fossil record and palaeobiogeography of the family. Zool J Linn Soc 2007, 149:701-716.

33. Ren D, Yin JC: New "osmylid-like" fossil Neuroptera from the Middle Jurassic of Inner Mongolia, China. J New York Entomol Soc 2003, 111:1-11.

34. Ren D: A new lacewing family (Neuroptera) from the Middle Jurassic of Inner Mongolia, China. Entomol Sin 2002, 9:53-67.

35. Makarkin VN: New names for the Jurassic Neuroptera. Paleontol Z 1990 $1: 120$

36. Wang YJ, Liu ZQ, Wang X, Shih CK, Zhao YY, Engel MS, Ren D: Ancient pinnate leaf mimesis among lacewings. Proc Natl Acad Sci U S A 2010, 107:16212-16215

37. Olofsson M, Vallin A, Jakobsson S, Wiklund C: Marginal eyespots on butterfly wings deflect bird attacks under low light intensities with UV wavelengths. PLoS One 2010, 5:e10798.

38. Krenn HW, Gereben-Krenn BA, Steinwender BM, Popov A: Flower-visiting Neuroptera: mouthparts and feeding behavior of Nemoptera sinuata (Nemopteridae). Euro J Entomol 2008, 105:267-277.

39. Nixon KC: WinClada ver. 1.00.08. Ithaca, NY: Published by the author; 2002.

40. Swofford DL: PAUP_Phylogenetic analysis using parsimony (and Other Methods). Sunderland, MA: Sinauer; 2002.

41. Sorenson MD, Franzosa EA: TreeRot. Version 3. Ann Arbor, Ml: University of Michigan; 2007.

42. Huelsenbeck JP, Ronquist F: MrBayes: bayesian inference of phylogeny. Bioinformatics 2001, 17:754-755

43. Ronquist F, Huelsenbeck JP, van der Mark P: MrBayes 3.1 Manual. Available at: http://mrbayes.sourceforge.net/wiki/index.php/Manual; 2005.

44. Lewis PO: A likelihood approach to estimating phylogeny from discrete morphological character data. Syst Biol 2001, 50:913-925.

doi:10.1186/1471-2148-14-126

Cite this article as: Yang et al:: Mesozoic lacewings from China provide phylogenetic insight into evolution of the Kalligrammatidae (Neuroptera). BMC Evolutionary Biology 2014 14:126. 